\title{
The 4-(Phenylsulfanyl) butan-2-one Improves Impaired Fear Memory Retrieval and Reduces Excessive Inflammatory Response in Triple Transgenic Alzheimer's Disease Mice
}

\section{OPEN ACCESS}

Edited by:

Franca Rosa Guerini,

Fondazione Don Carlo Gnocchi Onlus

(IRCCS), Italy

Reviewed by:

Aaron Wilber,

Florida State University, United States

Merina Varghese,

Icahn School of Medicine at Mount

Sinai, United States

${ }^{*}$ Correspondence:

Ingrid Y. Liu

ycliu@gms.tcu.edu.tw

Received: 08 October 2020 Accepted: 06 January 2021 Published: 03 February 2021

Citation:

Varinthra P, Ganesan K, Huang S-P, Chompoopong $S$, Eurtivong $C$

Suresh P, Wen Z-H and Liu IY (2021)

The 4-(Phenylsulfanyl) butan-2-one Improves Impaired Fear Memory Retrieval and Reduces Excessive Inflammatory Response in Triple Transgenic Alzheimer's Disease Mice. Front. Aging Neurosci. 13:615079. doi: 10.3389/fnagi.2021.615079

\section{Peeraporn Varinthra ${ }^{1}$, Kiruthika Ganesan ${ }^{2}$, Shun-Ping Huang ${ }^{2}$, Supin Chompoopong ${ }^{3}$, Chatchakorn Eurtivong ${ }^{4,5}$, Pavithra Suresh ${ }^{1}$, Zhi-Hong Wen ${ }^{6}$ and Ingrid Y. Liu ${ }^{1 *}$}

1 Institute of Medical Sciences, Tzu Chi University, Hualien, Taiwan, ${ }^{2}$ Department of Molecular Biology and Human Genetics, Tzu Chi University, Hualien, Taiwan, ${ }^{3}$ Department of Anatomy, Faculty of Medicine Siriraj Hospital, Mahidol University, Bangkok, Thailand, ${ }^{4}$ Program in Chemical Sciences, Chulabhorn Graduate Institute, Chulabhorn Royal Academy, Bangkok, Thailand, ${ }^{5}$ Center of Excellence on Environmental Health and Toxicology (EHT), Commission on Higher Education (CHE), Ministry of Education, Bangkok, Thailand, ${ }^{6}$ Department of Marine Biotechnology and Resources, National Sun Yat-sen University, Kaohsiung, Taiwan

Alzheimer's disease (AD) is a neurodegenerative disease characterized by an excessive inflammatory response and impaired memory retrieval, including spatial memory, recognition memory, and emotional memory. Acquisition and retrieval of fear memory help one avoid dangers and natural threats. Thus, it is crucial for survival. AD patients with impaired retrieval of fear memory are vulnerable to dangerous conditions. Excessive expression of inflammatory markers is known to impede synaptic transmission and reduce the efficiency of memory retrieval. In wild-type mice, reducing inflammation response can improve fear memory retrieval; however, this effect of this approach is not yet investigated in 3xTg-AD model mice. To date, no satisfactory drug or treatment can attenuate the symptoms of $A D$ despite numerous efforts. In the past few years, the direction of therapeutic drug development for AD has been shifted to natural compounds with anti-inflammatory effect. In the present study, we demonstrate that the compound 4-(phenylsulfanyl) butan-2-one (4-PSB-2) is effective in enhancing fear memory retrieval of wild-type and 3xTg-AD mice by reducing the expression of TNF- $\alpha$, COX-2, and iNOS. We also found that 4-PSB-2 helps increase dendritic spine density, postsynaptic density protein-95 (PSD-95) expression, and long-term potentiation (LTP) in the hippocampus of 3xTg-AD mice. Our study indicates that 4-PSB-2 may be developed as a promising therapeutic compound for treating fear memory impairment of AD patients.

Keywords: Alzheimer's disease, inflammation, 3xTg-AD, fear conditioning, 4-(phenylsulfanyl) butan-2-one, natural compound, hippocampus, CA3

\section{INTRODUCTION}

Alzheimer's disease (AD) is a neurodegenerative disorder known to involve neuronal inflammation (Newcombe et al., 2018) and impaired memory retrieval, including episodic memory, recognition memory, spatial memory (Serrano-Pozo et al., 2011; Wahl et al., 2017), and fearful and traumatic memory (Hamann et al., 2002). Retrieval of fear memory elicits a fear response that helps avoid 


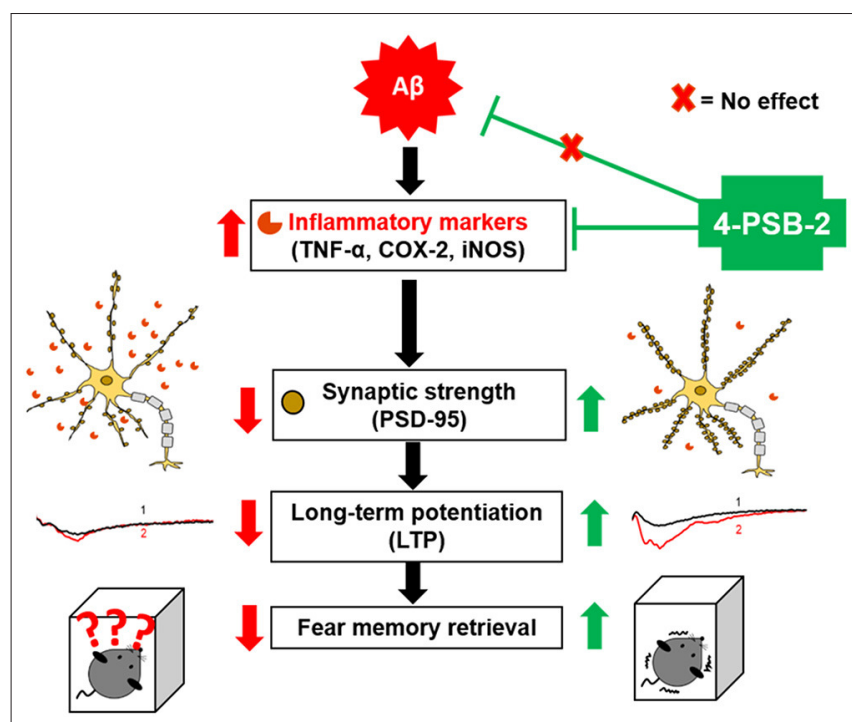

Graphical Abstract | Schematic abstract. We are the first to report that 4-PSB-2 acts as memory enhancer and anti-inflammatory compound, which can reverse impairments in fear memory retrieval in 3xTg-AD mice without changing $A \beta$ levels. 4-PSB-2 reduces the expression of several inflammatory markers including TNF- $\alpha$, COX-2, and iNOS, increases PSD-95 expression in the hippocampus, and improves synaptic dysfunction in 3xTg-AD mice, which may account for its effect in improving fear memory retrieval.

predators and natural threats. Thus, the fear response is important for survival, and the underlying neural circuits are highly conserved across species (Wotjak and Pape, 2013). Studies of $\mathrm{AD}$ patients have revealed that the fear response is defective at the onset stage of AD (Nasrouei et al., 2020). The AD model animals also exhibit impaired contextual fear memory (Billings et al., 2005; Kishimoto et al., 2017). An excessive inflammatory response is known to associate with impairments of working memory, remote memory stabilization, and spatial memory in AD (Murray et al., 2012; Wang et al., 2014; Mariani et al., 2017; Scuderi et al., 2018); however, its relationship with defective fear memory of AD is not clear yet.

The inflammatory response in the brain has been implicated in the initiation and progression of the pathogenesis of $\mathrm{AD}$ (Newcombe et al., 2018). The two AD pathological hallmarks, extracellular amyloid-beta $(\mathrm{A} \beta)$ deposition and intracellular neurofibrillary tangles, are known to increase inflammatory response and impede several types of memory functions, including episodic memory, recognition memory, semantic memory, spatial memory, and emotional memory (SerranoPozo et al., 2011; Klein-Koerkamp et al., 2012; Wahl et al., 2017). Early accumulation of $A \beta$ and tau tangles can also induce astrogliosis and microglial activation, resulting in the elevated expression of proinflammatory mediators, including interleukin$1 \beta$ (IL-1 $\beta$ ), tumor necrosis factor-alpha (TNF- $\alpha$ ), inducible nitric oxide synthase (iNOS), and interleukin-6 (IL-6) (Wang et al., 2015). Increases in these proinflammatory mediators can cause neurotoxicity, loss of synaptic transmission, reduced long-term potentiation (LTP) induction, and impaired cognitive functions in AD (Garwood et al., 2011; Fakhoury, 2018; Rajendran and
Paolicelli, 2018). Previous studies have demonstrated that fear memory retrieval deficit is related to the decrease of LTP induction in AD mouse models such as Tg2576 mice (Comery et al., 2005), APP/PS1 mice (Gu et al., 2016), and 5XFAD mice (Kimura and Ohno, 2009). To date, no drug or treatment can cure this disease or effectively reduce the symptoms in humans. Most clinical trials of drugs targeting the clearance of $\mathrm{A} \beta$ have had limited success and failed to rescue memory functions (Morrison, 2016), while reducing inflammatory responses seem to delay the onset of $\mathrm{AD}$ symptoms (Akiyama et al., 2000; Businaro et al., 2018). The nonsteroidal anti-inflammatory drugs (NSAIDs) have been used to prevent or delay the onset of $\mathrm{AD}$ (Zhang et al., 2018). However, it was not effective and caused various adverse side effects including gastrointestinal bleeding, hypertension, and nephrotoxicity in elderly patients (Wongrakpanich et al., 2018). Therefore, finding a compound that can effectively prevent or treat fear memory impairment and reduce (excessive inflammatory response) in $\mathrm{AD}$ with less side effect is in an urgent need.

The compound 4-PSB-2 initially extracted from the soft coral Cladiella australis, has been shown to have anti-melanogenic effects via the suppression of tyrosinase activity in zebrafish embryos (Wu et al., 2015), and antiinflammatory/neuroprotective effects with single-dose injection into a rat optic nerve crush model accompanied by reduced iNOS and cyclooxygenase-2 (COX-2) expression levels (Chien et al., 2016). Our recent study shows that $A \beta_{1-42}$ oligomers-induced elevation of inflammatory markers in retinal pigment epithelial cells can be attenuated with a single-dose application of 4-PSB-2. Administration of this compound significantly suppressed expressions of TNF- $\alpha$, COX-2, and iNOS (Varinthra et al., 2020). Besides, 4-PSB-2 is lipophilic; therefore, it is suitable as a drug candidate. According to all the 4-PSB-2 characteristics, we chose it to investigate whether reducing inflammation response in $\mathrm{AD}$ mice can improve impaired retrieval of fear memory. We injected the 4-PSB-2 into wild type and 3xTg-AD mice before fear memory testing. We found that this compound can effectively improve the deficit of contextual fear memory retrieval of the 3xTg-AD mice, reduce neuroinflammation response, and increase synaptic plasticity in the hippocampus.

\section{METHODS}

\section{Ethics Statement}

All protocols used in this study were reviewed and approved by the Institutional Animal Care and Use Committee of Tzu Chi University (TCU, \#108030), Taiwan and followed the guidelines of the Taiwan Ministry of Science and Technology on the ethical treatment of animals.

\section{Animals}

Six-month-old male wild-type C57BL/6 mice with some mixed SV129 genetic markers, initially provided by the National Laboratory Animal Centre (Taiwan), were purchased and maintained undisturbed in the Laboratory Animal Centre of Tzu Chi University. Six-month-old 3xTg-AD mice were provided by Hei-Jen Huang from the Department of Nursing, Mackay Junior 
College of Medicine, Nursing and Management (Taiwan), and Hsiu Mei Hsieh-Li from the Department of Life Science, National Taiwan Normal University (Taiwan). The 3xTg-AD mice, initially purchased from the Jackson Laboratory (Stock \#34830 JAX), harbor three mutations associated with $\mathrm{AD}$ and dementia in the genetic background of $\mathrm{C} 57 \mathrm{BL} / 6 ; 129$. The three mutations are two familial AD mutations (APP Swedish and PSEN1 M146V), and one mutation associated with frontotemporal dementia and parkinsonism-17 (tau P301L). Six-month-old male 3xTg-AD mice were used in this study. All mice were housed in individual plastic and metal cages in a temperature-controlled room with a 12-h light/dark cycle until the behavioral tasks were performed. Food and water were provided ad libitum.

\section{Preparation of 4-PSB-2 Solution and Treatment}

4-PSB-2 was provided by the Research Center of National Research Program for Biopharmaceuticals, Taiwan and its structure is shown in Figure 1A (Wen et al., 2014). 4-PSB-2 was dissolved in saline/DMSO at the ratio of 9:1. Three different concentrations $(5,10$, and $15 \mathrm{mg} / \mathrm{kg}$ ) of 4 -PSB-2 were used in this study. 4-PSB-2 was intraperitoneally injected into mice immediately after trace fear conditioning (TFC).

\section{Trace Fear Conditioning}

Wild-type (WT) mice were divided into two groups: (1) the WT group that did not undergo TFC and (2) the WT group that underwent TFC. Each group contained 3 subgroups $(n=$ 5/subgroup), which included mice injected with (1) saline, (2) saline + dimethyl sulfoxide (DMSO), or (3) $15 \mathrm{mg} / \mathrm{kg} 4$-PSB2. $3 \times$ Tg-AD mice ( $n=8-11$ /group) were divided into three groups: (1) the untreated $3 x \mathrm{Tg}-\mathrm{AD}$ group, (2) sham $3 \mathrm{xTg}-\mathrm{AD}$ group (saline $+\mathrm{DMSO}$ ), and (3) the $3 \mathrm{xTg}-\mathrm{AD}$ group treated with $15 \mathrm{mg} / \mathrm{kg}$ of 4 -PSB-2. Fear conditioning was performed as described previously (Pai et al., 2018). On days 1-3, WT mice ( $n=5$ /group) and $3 \times \mathrm{xTg}-\mathrm{AD}$ mice were habituated to the conditioning chamber for $15 \mathrm{~min}$ per day. On day 4 (TFC day), the mice were placed in the chamber for $2 \mathrm{~min}$ and exposed to three trials of a tone $(6,000 \mathrm{~Hz}, 85 \mathrm{~dB}$; conditional stimulus) for $20 \mathrm{~s}$ followed by a 10 -s interval and a 1 -s foot shock ( $2 \mathrm{~mA}$; unconditional stimulus). 4-PSB-2 was injected into mice immediately after TFC. Twenty-four hours later, the mice were placed in the same conditioning chamber for $6 \mathrm{~min}$ without the tone or foot shock for the contextual test. One hour later, the tone test was performed. The mice were placed in a new chamber for 1 min without a tone or foot shock and then exposed to a tone $(6,000 \mathrm{~Hz}, 85 \mathrm{~dB})$ for $6 \mathrm{~min}$. Freezing behaviors were recorded and analyzed by FreezeScan software (CleverSys, Inc., VA, USA), and the freezing percentage was calculated as (total freezing time/total test time) $\times 100$. Freezing behavior was characterized by the inhibition and absence of movement, heavy breathing, and minimal movement for normal respiration. Head scanning and sleeping were not considered freezing behaviors.

\section{Electrophysiological Recording}

After TFC, the WT and 3xTg-AD mice were anesthetized and immediately sacrificed followed by taking the whole brain to incubate in ice-cold artificial cerebrospinal fluid (ACSF). Then, the hippocampus was horizontally sectioned for about $350 \mu \mathrm{m}$ thickness by a vibrating microtome (Leica VT1000 S, Leica Biosystems Inc., Nussloch, Germany) in oxygenated (95\% $\mathrm{O}_{2} / 5 \% \mathrm{CO}_{2}$ ) ACSF. The hippocampal slices were incubated at $26^{\circ} \mathrm{C}$ for $2 \mathrm{~h}$ before recording. To induce LTP, the concentric bipolar tungsten electrodes and the recording glass pipettes with a micropipette puller were placed in the Schaffer collateralcommissural fibers at the stratum radiatum of the hippocampal CA1 region. During LTP inducing and recording, the slices were perfused continuously with ACSF at a speed of $20 \mathrm{rpm}$. The stimulation intensity was adjusted between 0 and $10 \mathrm{~V}$ for each slice. The field excitatory postsynaptic potentials (fEPSP) were elicited to approximately $50 \%$ of the maximal response. Before LTP induction, a steady baseline was recorded every $20 \mathrm{~s}$ for 20 min. LTP was evoked by high-frequency stimulation (HFS) for 3 trials of $100 \mathrm{~Hz}$ with a $20 \mathrm{~s}$ interval between each trial for $60 \mathrm{~s}$. Then, fEPSPs were stimulated every $20 \mathrm{~s}$ for $60 \mathrm{~min}$. The signals were amplified by an Axon Multiclamp 700B amplifier (Axon Instruments, Foster City, CA), acquired at $10 \mathrm{kHz}$ by an Axon Digidata 1550B plus HumSilencer (Axon Instruments, Foster City, CA) and filtered at $1 \mathrm{kHz}$. The slope of fEPSPs is measured using Axon pCLAMP 11 electrophysiology data acquisition and analysis software.

\section{Western Blot Analysis}

The mice were sacrificed by decapitation immediately after TFC to collect the hippocampi. The hippocampi were then homogenized in an ice-cold RIPA lysis buffer containing phosphatase and protease inhibitors (F. Hoffmann-La Roche AG, Basel, Switzerland). The samples were sonicated and centrifuged for $15 \mathrm{~min}$ at $13,500 \times \mathrm{g}$ at $4^{\circ} \mathrm{C}$. The supernatants were collected, and the protein concentration was measured with the Bradford protein assay (Bio-Rad Laboratories, USA). Equal amounts of proteins from hippocampal tissues were separated by $10 \%$ sodium dodecyl sulfate-polyacrylamide gel electrophoresis (SDS-PAGE) and transferred to nitrocellulose membranes. The membranes were blocked with $1 \%$ bovine serum albumin (BSA) for $1 \mathrm{~h}$ at room temperature and incubated overnight at $4{ }^{\circ} \mathrm{C}$ with the following primary antibodies: mouse anti-PSD-95 (1:2,000, MA1-045, Thermo Fisher Scientific) and mouse anti- $\beta$-actin (1:10,000, A5441, Sigma-Aldrich). After that, the membranes were washed three times with $1 \mathrm{X}$ phosphatebuffered saline (PBS) containing $0.1 \%$ Tween-20 and incubated with a horseradish peroxidase-conjugated (HRP) anti-mouse antibody $(1: 10,000,7076$, cell signaling technology) for $1 \mathrm{~h}$ at room temperature. The proteins of specific molecular weights were visualized using enhanced chemiluminescence reagents (Western Lightning ${ }^{\circledR}$ Plus-ECL, PerkinElmer, MA, USA) and detected by a UVP BioSpectrum 810 imaging system. Band intensity was quantified using ImageJ software (downloaded from National Institutes of Health, Bethesda, MD, USA, https://imagej.nih.gov/ij/download.html). 
A<smiles>CC(=O)CCSc1ccccc1</smiles>

4-PSB-2

B

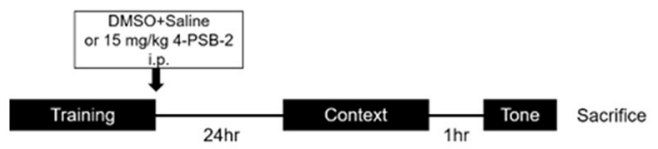

E

D

\begin{abstract}
TFC- learning curve
\end{abstract}
$\star$ Saline - Saline+DMSO

$\rightarrow 15 \mathrm{mg}$ 4-PSB-2

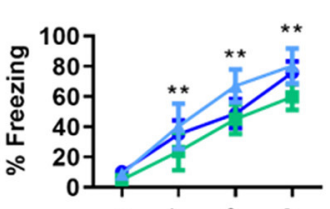

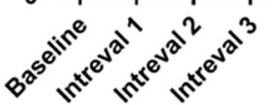

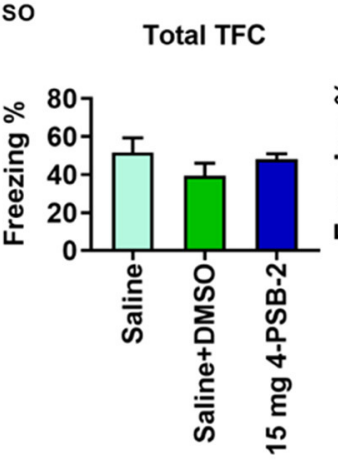

C
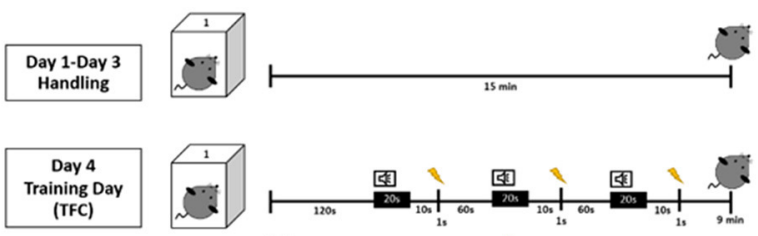

四 Tone: $6000 \mathrm{~Hz}, 85 \mathrm{~dB}$ Foot shock: $2 \mathrm{~mA}$

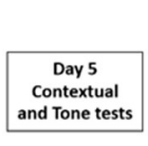

F

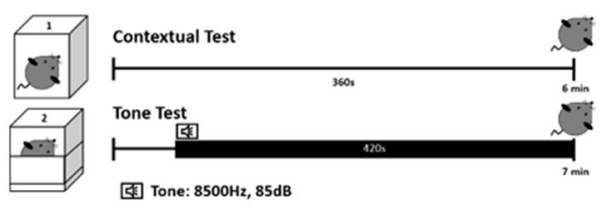

G

\section{Contextual Test}

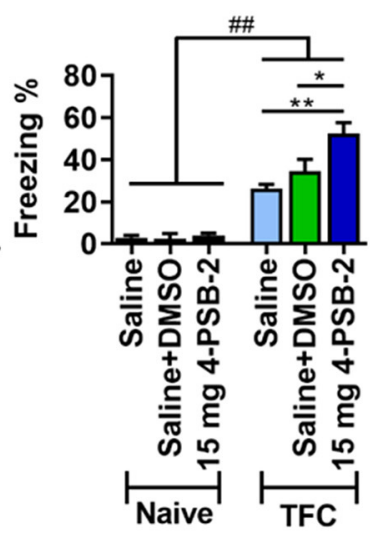

Tone Test

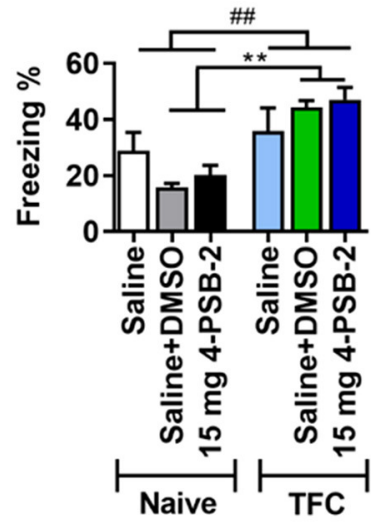

H

$15 \mathrm{mg} / \mathrm{kg}$ 4-PSB-2

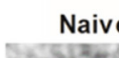

Naive

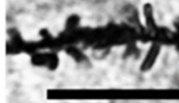

Saline+DMSO

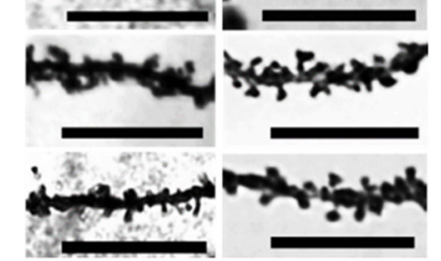

TFC

I

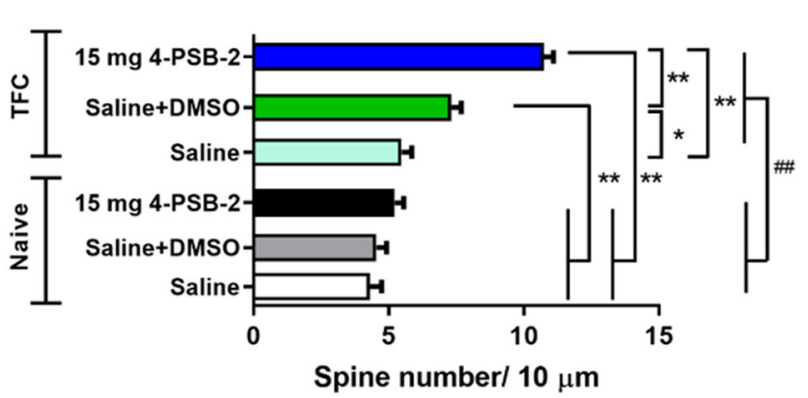

FIGURE 1 | 4-PSB-2 increased fear memory retrieval and dendritic spine density in the hippocampi of wild type (WT) mice. (A) The chemical structure of 4-PSB-2. (B) The timeline of 4-PSB-2 injection and TFC training. The WT mice were subjected to trace fear conditioning (TFC) and then immediately treated with 4-PSB-2. Contextual fear memory was tested $24 \mathrm{~h}$ later, and then a tone memory test was performed after a 1 - $\mathrm{h}$ interval. (C) TFC protocol. The WT mice were handled in the conditioning chamber for 3 days before TFC. On day 4 , the WT mice received 3 trials of TFC. Twenty-four hours later, their freezing responses to context were tested by placing them into the same conditioning chamber for $6 \mathrm{~min}$, and then the tone memory test was performed in a different chamber for 6 min after a 1-h interval. (D) The WT mice acquired TFC when compared the freezing percentage at intervals 1-3 with baseline performance. (E) The results revealed that all groups were not significantly different in freezing percentage of total TFC. (F) There was a statistically significant interaction between the effects of TFC and treatments on freezing percentage change of contextual test in WT mice. The 4-PSB-2 injection at a concentration of $15 \mathrm{mg} / \mathrm{kg}$ significantly increased the retrieval of contextual fear memory and (G) slightly enhanced memory retrieval of a tone. (H,I) Among the trace fear-conditioned mice, the WT mice injected with 4-PSB-2 showed a significant increase in apical dendritic spine density. The number of WT mice in each group for TFC is shown. Naiive: saline $(n=4)$, saline + DMSO $(n=5), 15 \mathrm{mg} 4$-PSB-2 $(n=5)$; TFC: saline $(n=4)$, saline + DMSO $(n=5), 15 \mathrm{mg}$ 4-PSB-2 $(n=5) \cdot n=2$ /group for Golgi-COX staining. The results are shown in (D-G) and (I) are plotted as the means \pm SEMs and were statistically analyzed by mixed-design repeated-measures ANOVA followed by Bonferroni test for (D); two-way ANOVA followed by Tukey's test for $(\mathbf{F}, \mathbf{G}, \mathbf{I}), \# \#$ indicates $p \leq 0.001$ between the factors; one-way ANOVA followed by Tukey's test for (E), ${ }^{*}$ Indicates $p \leq 0.05$, and ${ }^{*}$ Indicates $p \leq 0.001$ between the groups. Bar $=10 \mu \mathrm{m}$. 


\section{Immunohistochemical Staining and Image Analysis}

The hippocampi were taken at bregma -1.28 to $-2.92 \mathrm{~mm}$, then fixed with $4 \%$ paraformaldehyde (PFA) overnight at room temperature. After post-fixation, the brains were soaked in $30 \%$ sucrose at $4^{\circ} \mathrm{C}$ and cut coronally with cryostat every $20 \mu \mathrm{m}$. And then, the slides were fixed in methanol for $5 \mathrm{~min}$ at $4{ }^{\circ} \mathrm{C}$ and dried at room temperature. Next, they were blocked with $1 \mathrm{x}$ PBS containing 2\% BSA and $0.3 \%$ Triton X100 for $2 \mathrm{~h}$ at room temperature and incubated with primary antibody: rabbit anti-TNF-alpha (1:300, ab6671, Abcam), rabbit anti-COX-2 (1:300, 12282, cell signaling technology), rabbit anti-iNOS (1:300, PA1-036, Thermo Fisher scientific), mouse anti-MAP2 (1:200, ab11267, Abcam), goat anti-GFAP (1:200, ab53554, abcam), goat anti-IBA1 (1:200, NB100-1028, Novus Biologicals), and rabbit anti-A11 (1:200, AHB0052, Thermo Fisher scientific), at $4^{\circ} \mathrm{C}$, overnight. Sections washed in $1 \mathrm{x}$ PBS containing $0.3 \%$ Triton $\mathrm{X}-100$ three times for $10 \mathrm{~min}$ and then incubated with the secondary antibody: Alexa 594 or Alexa 488 goat anti-rabbit IgG or goat anti-mouse (1:300, A-11037, A-11034, A-11056, A-11003, Thermo Fisher scientific, USA) or Donkey anti-goat IgG (1:300, ab150129, Abcam) for $1 \mathrm{~h}$ at room temperature in darkness. Sections were then again washed with $1 \mathrm{x}$ PBS containing $0.3 \%$ Triton X-100 three times for $10 \mathrm{~min}$ each, dried in room temperature, mounted with Fluoromount ${ }^{\mathrm{TM}}$ aqueous mounting medium, coverslipped and examined under fluorescence microscopy with 40X and 100X objective lens (Nikon ECLIPSE Ni-E). For calculating the positive area percentage of each antibody, $3-5$ fields $(200 \times 200 \mu \mathrm{m})$ from 3 to 4 sections per mouse were quantified using ImageJ software (downloaded from National Institutes of Health, Bethesda, MD, USA, https://imagej.nih.gov/ij/download.html).

\section{Golgi-Cox Staining for Dendritic Spine Staining and Density Measurement}

Mice were perfused transcardially with $0.9 \%$ saline followed by $4 \%$ PFA. After that, the whole brain was collected and fixed in $4 \%$ PFA overnight at room temperature. Next, the brains were transferred to Golgi-Cox solution and performed the staining process as previously described (Gibb and Kolb, 1998) for 5 days at $32^{\circ} \mathrm{C}$. Then, the brains were transferred to $30 \%$ sucrose solution. The brains were sectioned at a thickness of $60 \mu \mathrm{m}$ using a vibratome, and 5 sections/brain were collected for examination. Each group consisted of two animals, for each brain, 5 sections were chosen and 6 neurons from each section (3 from left, 3 from the right hippocampus-including DG and CA1) were selected for spine analysis. Neurons with properly stained dendrites were selected and the second to sixth proximal branch of apical dendrites were taken for spine counting. Spines were counted manually using ImageJ (downloaded from National Institutes of Health, Bethesda, MD, USA, website: https://imagej.nih.gov/ij/ download.html). Spine density was represented as the number of spines per $10 \mu \mathrm{m}$ of dendrite for 30-60 dendritic segments per group.

\section{Molecular Descriptor Calculation}

The chemical structure of 4-PSB-2 was analyzed by using the Dragon 7.0 software suite (Kode Chemoinformatics, Pisa, Italy). Dragon 7.0 software is widely used to calculate molecular descriptors in scientific research (Kawczak et al., 2018), including molecular weight (MW); Moriguchi $\log \mathrm{P}(M \log \mathrm{P})$; hydrogen bond donors (HDs), and hydrogen bond acceptors (HAs), which are neighboring electronegative ions bearing a lone pair of electrons; the number of rotatable bonds (RBN); and total polar surface area (TPSA).

\section{Statistical Analysis}

The mean \pm standard error of the mean (mean \pm SEM) of the data from this study was calculated and are plotted. The freezing percentage of total TFC, contextual and tone tests, locomotor activity, western blotting, immunohistochemical staining, and electrophysiological recording data in $3 \times \mathrm{Tg}-\mathrm{AD}$ mice and $\mathrm{WT}$ -untreated were analyzed by one-way ANOVA followed by Tukey's post hoc test for multiple comparisons. The freezing percentage of contextual and tone tests, and synaptic spine density data in WT mice were analyzed the interaction of 2 factors including TFC and treatments on freezing percentage by two-way ANOVA followed by Tukey's post hoc test for multiple comparisons. The freezing percentage of the TFC learning curve of WT and 3xTg-AD mice were analyzed by mixeddesign repeated-measures ANOVA followed by Bonferroni posthoc test for multiple comparisons. Statistical significance of the differences among the groups was established at a $P$-value $<0.05$. All graphs were plotted with GraphPad Prism 8.0 software.

\section{RESULTS}

\section{Chemical Structure Properties of 4-PSB-2}

The compound 4-PSB-2 was initially extracted from a soft coral Cladiella australis, then modified and synthesized by the Development Center for Biotechnology (Taiwan), the National Research Program for Biopharmaceuticals support (CS-1-G-103002). To investigate the chemical structure properties of 4-PSB-2 (Figure 1A) and its potential for use as a therapeutic agent, the Dragon 7.0 software suite was used. Descriptors were calculated based on Lipinski's rules and are listed in Table 1. Lipinski's rules are a set of indicators of a compound's oral bioavailability,

TABLE 1 | The calculated molecular descriptors of 4-PSB-2.

\begin{tabular}{lc}
\hline Molecular Descriptors & 4-PSB-2 \\
\hline MW (g/mol) & 180.29 \\
RBN & 4 \\
MlogP & 2.723 \\
HD & 0 \\
HA & 1 \\
TPSA (Å2) & 42.37
\end{tabular}

MW, Molecular weight; RBN, number of rotatable bonds; MlogP, Moriguchi log P; HDs, Hydrogen bond donors; HAs, Hydrogen bond acceptors; TPSA, Total polar surface area. 
including a $\mathrm{MW}<500 \mathrm{~g} / \mathrm{mol}, \mathrm{RBN}<10, \mathrm{Mlog} \mathrm{P}<4.15$, $\mathrm{HD}<$ $5, \mathrm{HA}<10$, and TPSA $<140 \AA 2$. From Table 1, it is clear that the 4-PSB-2 obeys Lipinski's rules and is likely to show acceptable oral bioavailability. In particular, 4-PSB-2 has low TPSA and high $M \log$ P, indicating that it is lipophilic; thus was chosen for use in this study.

\section{4-PSB-2 Enhanced the Retrieval of Contextual Fear Memory and Increased Hippocampal Dendritic Spine Density in Wild-Type Mice}

To investigate the effect of 4-PSB-2 on fear memory retrieval following TFC, mice were exposed to TFC training and then immediately treated with saline+DMSO or 4-PSB-2 (Figure 1B). Twenty-four hours later, a contextual fear memory was tested by returning the mice to the same conditioning chamber without any tone or foot shock. One hour after the contextual test, memory for the tone was tested by placing the mice in a different chamber and exposing them to tone cue for $6 \mathrm{~min}$ without delivering any electric footshock (Figure 1C). The percentage of freezing indicated fear memory retrieval of the context and tone. A higher freezing percentage indicated better memory retrieval. The WT mice acquired TFC when compared the freezing percentage at intervals $1-3$ with baseline performance $\left[F_{(3,33)}=38.767, p<0.001\right.$; Figure 1D]. The results revealed that all groups were not significantly different in freezing percentage of total $\operatorname{TFC}\left[F_{(2,11)}=1.168, p=0.347\right.$; Figure 1E $]$. There was a statistically significant interaction between the effects of TFC and treatments on freezing percentage change of contextual test in WT mice $\left[F_{(2,22)}=6.136, p<0.01\right]$. Administration of $15 \mathrm{mg} / \mathrm{kg} 4$-PSB-2 significantly enhanced the fear memory retrieval to context in WT mice $[p<0.001$; Figure 1F]. There was a statistically significant interaction between the effect of TFC $\left[F_{(1,22)}=31.045, p<0.001\right]$ but not treatments $\left[F_{(2,22)}\right.$ $=0.334, p=0.72]$, on freezing percentage change of tone test in WT mice. Besides, the compound slightly enhanced fear memory retrieval to tone, although the effect was not statistically significant. Whereas, Naïve treated with saline + DMSO, Naïve treated with $15 \mathrm{mg} / \mathrm{kg}$ 4-PSB-2, TFC treated with saline + DMSO, and TFC treated with $15 \mathrm{mg} / \mathrm{kg}$ 4-PSB-2 groups showed a significant difference in fear memory retrieval to tone $(p<$ 0.001; Figure 1G). 4-PSB-2 administration did not cause any impairment of locomotor activity, sociability, or anxiety in WT mice (Supplementary Material and Supplementary Figure 1).

To further verify the effect of 4-PSB-2 on memory retrieval in WT mice at the cellular level, dendritic spine density in the hippocampal region was evaluated using Golgi-Cox staining. The results indicated that at a concentration of $15 \mathrm{mg} / \mathrm{kg}, 4-\mathrm{PSB}-2$ significantly increased the apical dendritic spine density in the hippocampi of WT mice (Figure 1H). There was a statistically significant interaction between the effects of TFC and treatments on dendritic spine density in WT mice $\left[F_{(2,283)}=18.65, p<\right.$ $0.001]$. Dendritic spine density of naïve mice was not changed after saline + DMSO and 4-PSB-2 treatments. After TFC, WT mice treated with saline + DMSO showed significantly increased dendritic spine density than naïve and the TFC + saline groups.
Treatment with $4-\mathrm{PSB}-2$ at $15 \mathrm{mg} / \mathrm{kg}$ to WT mice after TFC significantly increased the dendritic spine density compared with naïve groups and TFC groups ( $p<0.001$; Figure 1I).

\section{4-PSB-2 Injection Into 3xTg-AD Mice Rescued Impaired Fear Memory Retrieval to Context and Improved the Synaptic Dysfunction in 3xTg-AD Mice}

Since 4-PSB-2 at $15 \mathrm{mg} / \mathrm{kg}$ significantly enhanced the retrieval of contextual memory in WT mice (Figure 1F), we further tested whether it rescues impaired fear contextual memory in $3 \mathrm{xTg}$ $\mathrm{AD}$ mice at this dose. $3 \times \mathrm{Tg}-\mathrm{AD}$ mice exhibited $\mathrm{A} \beta$ deposition within neuronal and glial cells in the neocortex by 4 months and in the CA1 subregion of the hippocampus by 6 months (Oddo et al., 2003). The animals demonstrated impaired contextual fear and spatial memory at approximately 6 months of age (Billings et al., 2005). We injected 4-PSB-2 into 6-month-old 3xTg-AD mice immediately after TFC training and measured its effect on memory. After administration, 4-PSB-2 did not cause any impairment of locomotor activity in $3 \mathrm{xTg}-\mathrm{AD}$ mice $\left[F_{(3,34)}=\right.$ $1.048, p=0.384$; Figure 2A, $F_{(3,34)}=1.09, p=0.367$; Figure 2B]. The WT-untreated and $3 \mathrm{xTg}-\mathrm{AD}$ mice acquired TFC when compared the freezing percentage at intervals $1-3$ with baseline performance $\left[F_{(3,102)}=173.291, p<0.001\right.$; Figure $\left.2 \mathrm{C}\right]$. The behavioral results demonstrated that the total freezing percentage of all groups after TFC was similar $\left[F_{(3,34)}=0.828, p=\right.$ 0.488 ; Figure 2D], but the retrieval of contextual memory was impaired in the $3 \mathrm{xTg}-\mathrm{AD}$ mice compared to the untreated WT mice. Injection of 4-PSB-2 significantly enhanced the retrieval of contextual memory of the $3 \mathrm{xTg}-\mathrm{AD}$ mice compared to that of the untreated $3 \mathrm{xTg}-\mathrm{AD}$ and sham mice. Moreover, the $3 \mathrm{xTg}-\mathrm{AD}$ mice treated with 4-PSB-2 showed a significantly higher level of freezing to context than the untreated WT group $\left[F_{(3,34)}=20.07\right.$, $p<0.001$; Figure 2E]. Compared to the untreated WT mice, the $3 \mathrm{xTg}-\mathrm{AD}$ mice did not show significantly impaired memory retrieval of the tone. However, 3xTg-AD mice treated with 4PSB-2 exhibited significantly increased memory retrieval to tone $\left[F_{(3,34)}=2.735, p=0.059\right.$; Figure 2F $]$.

As shown in Figure 1, $15 \mathrm{mg} / \mathrm{kg}$ 4-PSB-2 significantly increased the apical dendritic spine density in WT mice, we next asked what is the effect of 4-PSB-2 on PSD-95 expression in $3 \times$ Tg-AD mice. Since PSD-95 is the major scaffolding protein at the excitatory postsynaptic density, a potent regulator of synaptic strength, and is known to be required for retrieval and stability of fear memory (Fitzgerald et al., 2015), we detected PSD-95 as an indirect synaptic marker in total protein samples extracted from the hippocampi of $3 \times \mathrm{Tg}-\mathrm{AD}$ mice after TFC. Western blot analysis indicated that the PSD-95 expression level was significantly reduced in the untreated sham $3 \times \mathrm{Tg}$ $\mathrm{AD}$ mice compared with the WT mice $\left[F_{(3,15)}=7.601, p<\right.$ 0.01; Figure 2G]. However, it was significantly enhanced after injection of 4-PSB-2 compared with that in the untreated and sham groups.

To further confirm the effect of 4-PSB-2 on synaptic plasticity in $3 \mathrm{xTg}-\mathrm{AD}$ mice at the cellular level, LTP recording was performed after TFC. The results revealed that fEPSP after LTP 


\section{Locomotor activity}

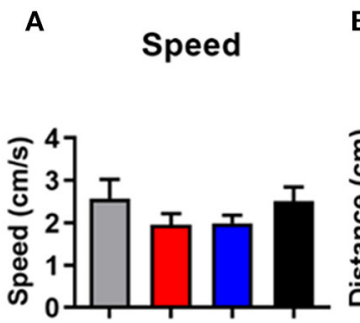

E B

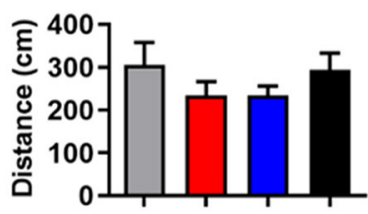

$\mathbf{F}$

TFC-Contexual Test
Distance

C

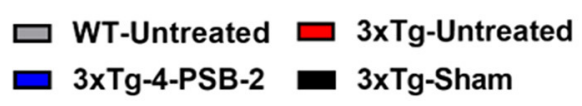

3xTg-4-PSB-2

D

$\rightarrow$ WT-Untreated - - $3 \times$ Tg-Untreated

$\leftarrow 3 \times T g-4-P S B-2 \multimap 3 \times T g-S h a m$
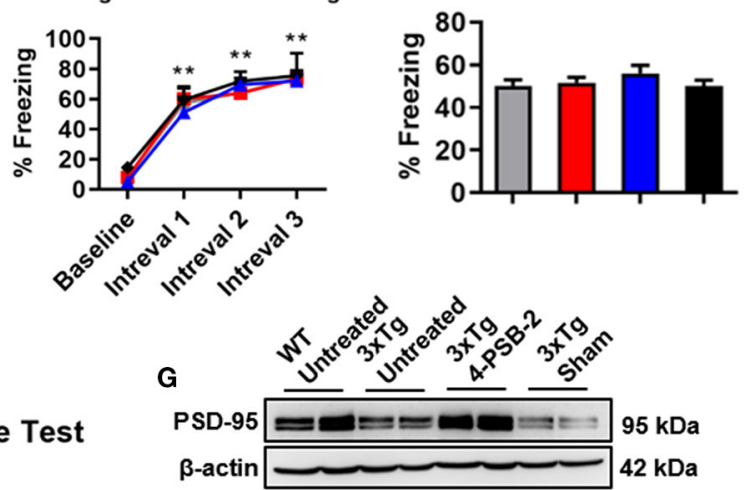

TFC-Tone Test
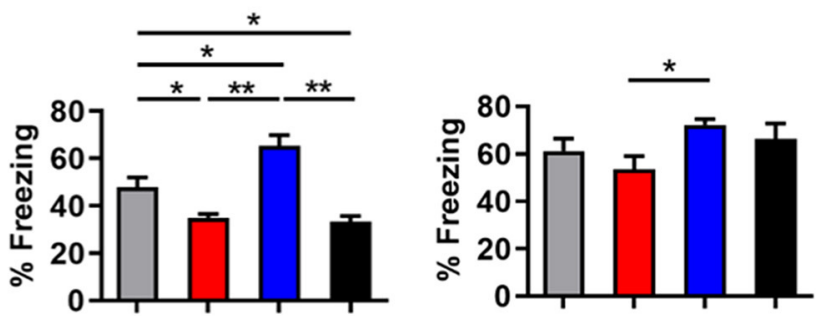

H
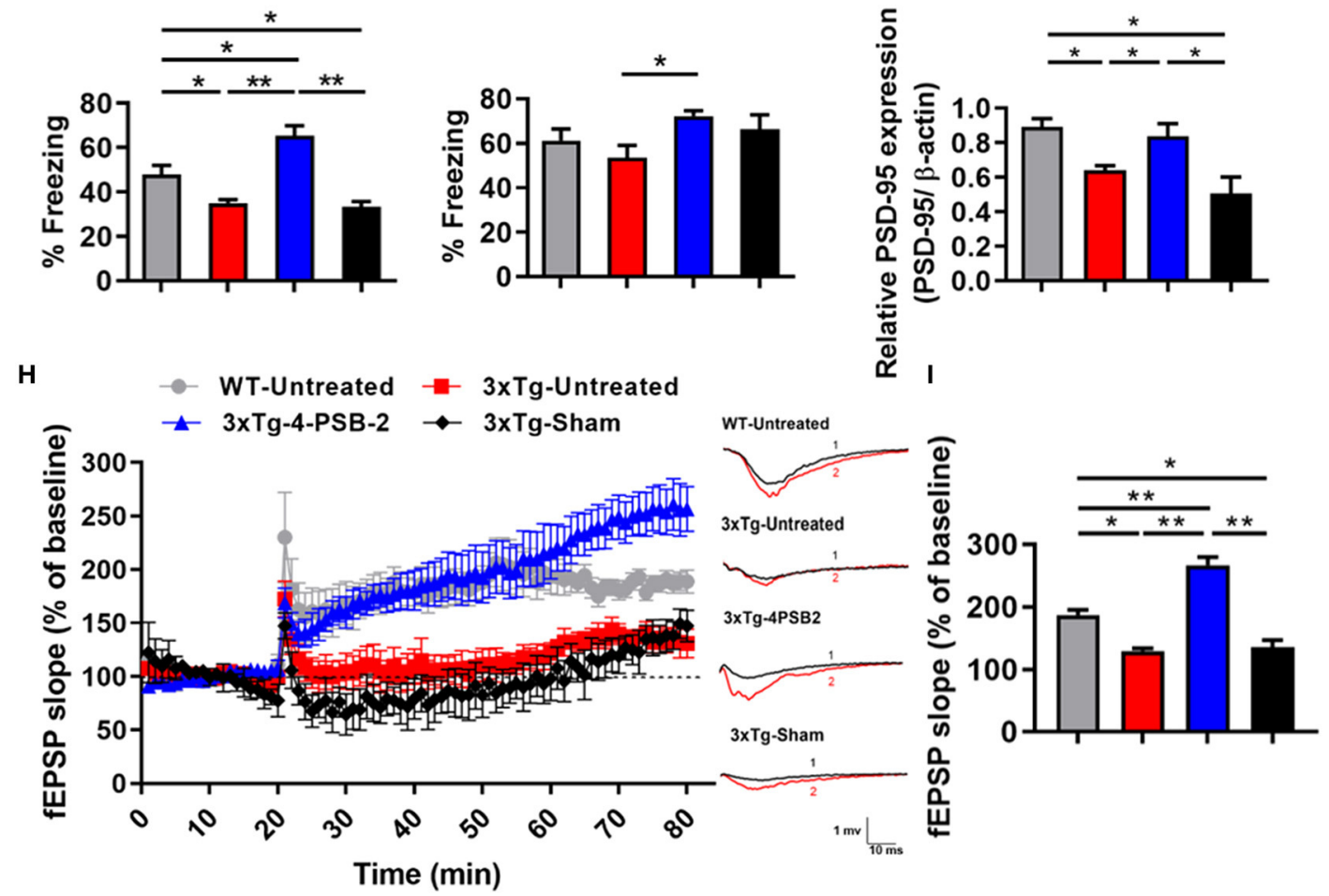

FIGURE 2 | 4-PSB-2 reversed contextual memory retrieval deficit and increased PSD-95 expression and synaptic plasticity in 3xTg-AD mice. (A,B) The locomotor activity of WT and 3xTg-AD mice was not significantly different before and after 4-PSB-2 injection. (C) The WT and 3xTg-AD mice acquired TFC when compared the freezing percentage at intervals 1-3 with baseline performance. (D) The 3xTg-AD mice were subjected to TFC training, and all groups appeared to learn normally. (E) The sham 3xTg-AD group exhibited reduced contextual memory retrieval compared to that of the untreated WT group, and the contextual memory retrieval and (F) memory retrieval of a tone of the 4-PSB-2-injected 3xTg-AD mice was significantly increased compared to that of the untreated 3xTg-AD mice. (G) Western blot analysis showed that PSD-95 expression levels in the hippocampi of the untreated 3xTg-AD and 3xTg-AD sham groups were significantly decreased compared to those in the untreated WT and were significantly increased after the administration of 4-PSB-2. (H) LTP was measured in the CA1 region of hippocampal sections of 3xTg-AD mice or WT mice with/without 4-PSB-2 administration for $60 \mathrm{~min}$. (I) Last 10 min of the first hour after LTP induction, 4-PSB-2 injection showed restoration of LTP deficit in 3xTg-AD mice and also higher than WT mice. The results are plotted as the means \pm SEMs and were statistically analyzed by mixed-design repeated-measures ANOVA followed by Bonferroni test for $\mathbf{( C )}$; one-way ANOVA followed by Tukey's test for (A,B) and (D-I). *Indicates $p \leq 0.05$, and **Indicates $p \leq 0.001$ between the groups; $n=8-11$ /group for TFC, $n=4-5 /$ group for western blot analysis, and $n=3-5 /$ group for LTP. 


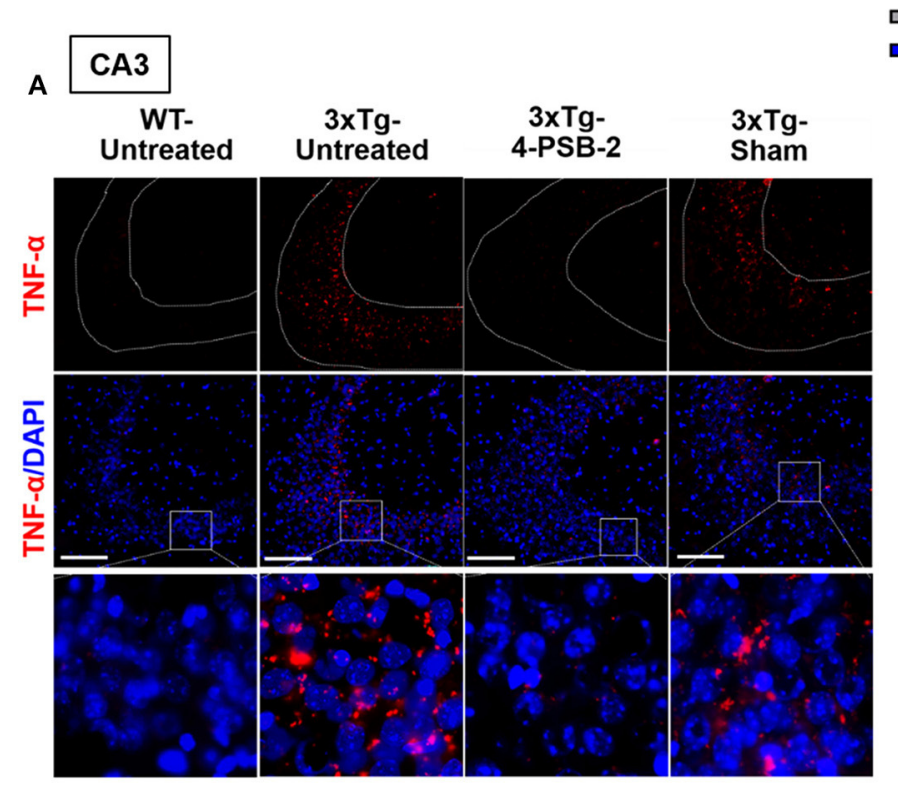

C AMYGDALA

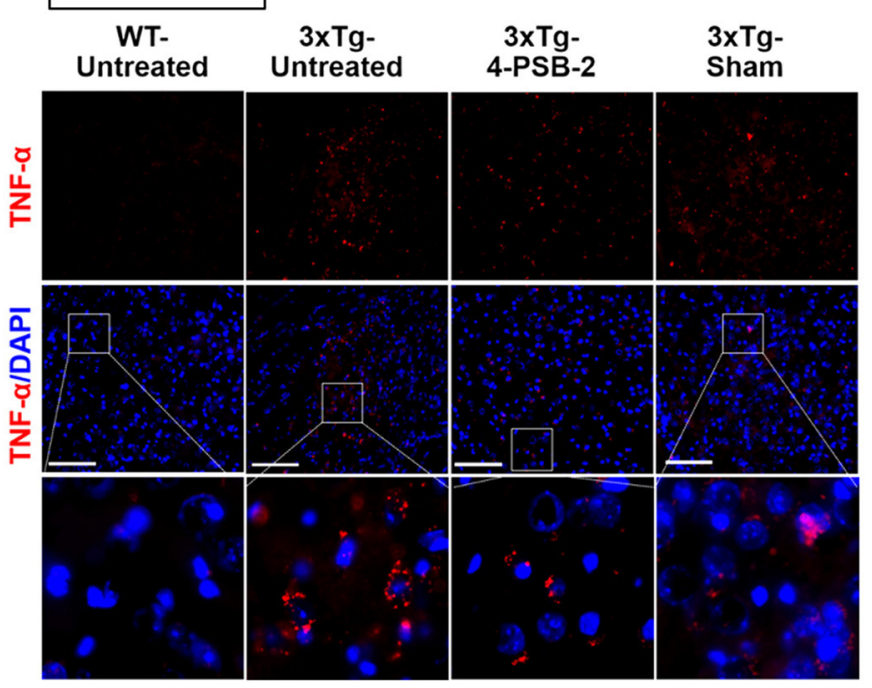

$\square$ WT-Untreated $\square 3 x T g-U n t r e a t e d$

3xTg-4-PSB-2 3xTg-Sham

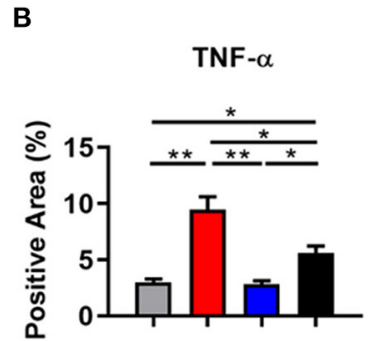

D

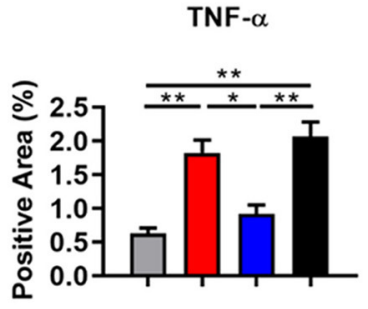

FIGURE 3 | 4-PSB-2 suppressed TNF- $\alpha$ expression in the hippocampal CA3 region and BLA of 3xTg-AD mice after TFC. (A) Immunofluorescence staining and (B) the quantitative result of TNF- $\alpha$ in the hippocampal CA3 region were significantly increased in the untreated $3 \times T$ Tg-AD and sham groups and were significantly decreased after 4-PSB-2 administration. (C,D) The expression of TNF- $\alpha$ in the BLA was significantly increased in the untreated 3xTg-AD and sham groups and was significantly decreased after the administration of 4-PSB-2. The results are plotted as the means \pm SEMs. *Indicates $p \leq 0.05$, and **Indicates $p \leq 0.001$ between the groups. TNF- $\alpha$ (red) and DAPI (blue) (nuclei). Bar $=100 \mu \mathrm{m}$, and $n=3-5 /$ group.

induction in untreated $3 \times \mathrm{Tg}-\mathrm{AD}$ and sham mice significantly decreased when compared with the untreated WT group. However, the injection of 4-PSB-2 significantly enhanced fEPSP after LTP induction of the $3 \times \mathrm{Tg}-\mathrm{AD}$ mice compared to the untreated 3xTg-AD and sham mice. Furthermore, fEPSP after LTP induction in the $3 \times \mathrm{Tg}$-AD mice treated with 4-PSB-2 showed a significantly higher than the untreated WT group $\left[F_{(3,12)}=\right.$ 40.601, $p<0.001$; Figures 2H,I].
4-PSB-2 Reduced the Expression Levels of Inflammatory Markers in the Hippocampal CA3 Region and Basolateral Amygdala

Since 4-PSB-2 appeared to be effective in rescuing impaired memory retrieval in $3 \mathrm{xTg}-\mathrm{AD}$ mice, we next asked whether memory retrieval is linked to expression changes in inflammatory markers in the involved brain region(s). We focused on the hippocampal region and basolateral amygdala (BLA) because 
these are the brain areas that play major roles in fear memory formation. The brains of WT and 3xTg-AD mice were collected after TFC and sectioned for immunohistochemical staining. The results revealed that in the hippocampal CA3 region, the expression levels of inflammatory molecules including TNF- $\alpha$ $\left[F_{(3,55)}=40.375, p<0.001\right.$; Figures 3A,B $]$, COX-2 $\left[F_{(3,41)}\right.$ $=9.779, p<0.001$; Figures 4A,B $]$, and iNOS $\left[F_{(3,58)}=\right.$ 11.68, $p<0.001$; Figures 5A,B], were significantly increased in the untreated and sham $3 \mathrm{xTg}-\mathrm{AD}$ group compared with the untreated WT mice. Administration of $15 \mathrm{mg} / \mathrm{kg} 4-\mathrm{PSB}-2$ significantly reduced the inflammatory cytokines expression levels. In the BLA, the expression levels of TNF- $\alpha\left[F_{(3,123)}=\right.$ $17.713, p<0.001$; Figures 3C,D], COX-2 $\left[F_{(3,47)}=5.485, p\right.$ $<0.01$; Figures 4C,D], and iNOS $\left[F_{(3,53)}=8.982, p<0.001\right.$; Figures 5C,D] were also increased in the untreated and sham $3 \mathrm{xTg}-\mathrm{AD}$ groups and were reduced by 4 -PSB- 2 treatment. The expression levels of COX-2 but not TNF- $\alpha$ and iNOS in sham $3 \mathrm{xTg}-\mathrm{AD}$ mice were significantly increased in the hippocampal
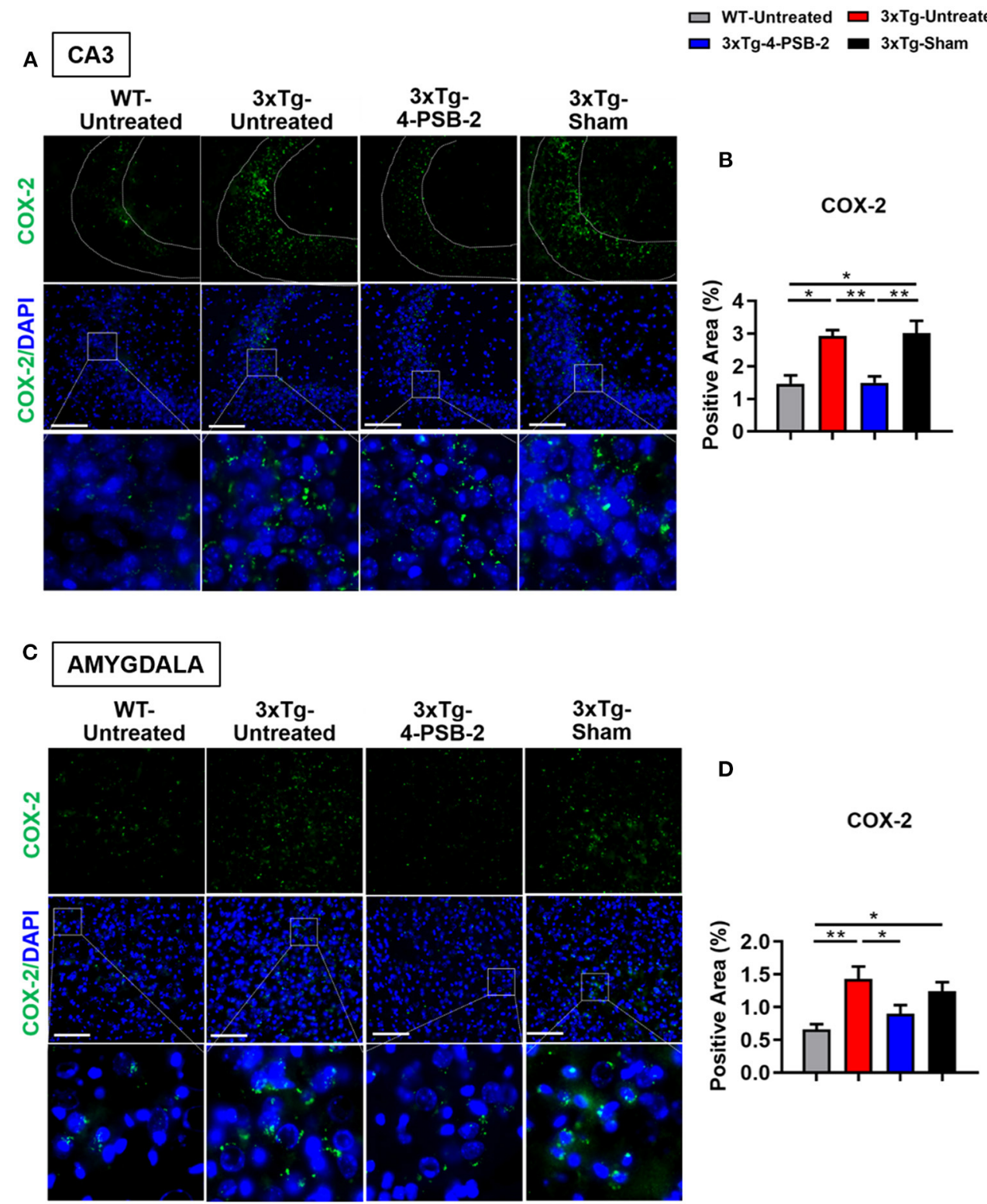

FIGURE 4 | 4-PSB-2 suppressed COX-2 expression in the hippocampal CA3 region and BLA of 3xTg-AD mice after TFC. (A,B) The expression of COX-2 in the hippocampal CA3 region was significantly increased in the untreated 3xTg-AD and sham groups and was significantly decreased after 4-PSB-2 administration. (C,D) The expression of COX-2 in the BLA of the untreated 3XTg-AD and sham groups were upregulated after TFC. After 4-PSB-2 administration, COX-2 expression was suppressed (compared with that in the untreated $3 \times \mathrm{Tg}$-AD group). The results are plotted as the means $\pm \mathrm{SEMs}$. ${ }^{*}$ indicates $p \leq 0.05$, and ${ }^{\star \star} \mid \mathrm{ndicates} p \leq 0.001$ between the groups. COX-2 (green) and DAPI (blue) (nuclei). Bar $=100 \mu \mathrm{m}$, and $n=3-5 /$ group. 


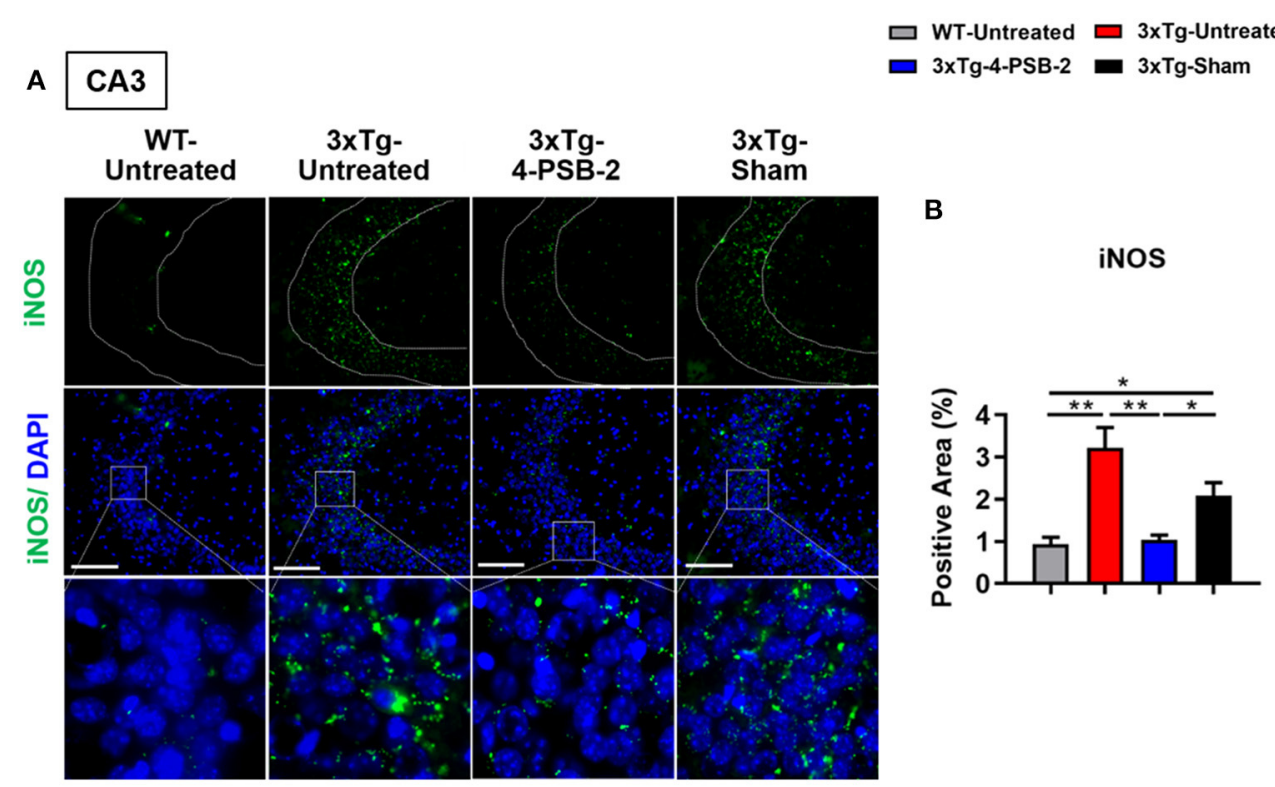

\section{AMYGDALA}
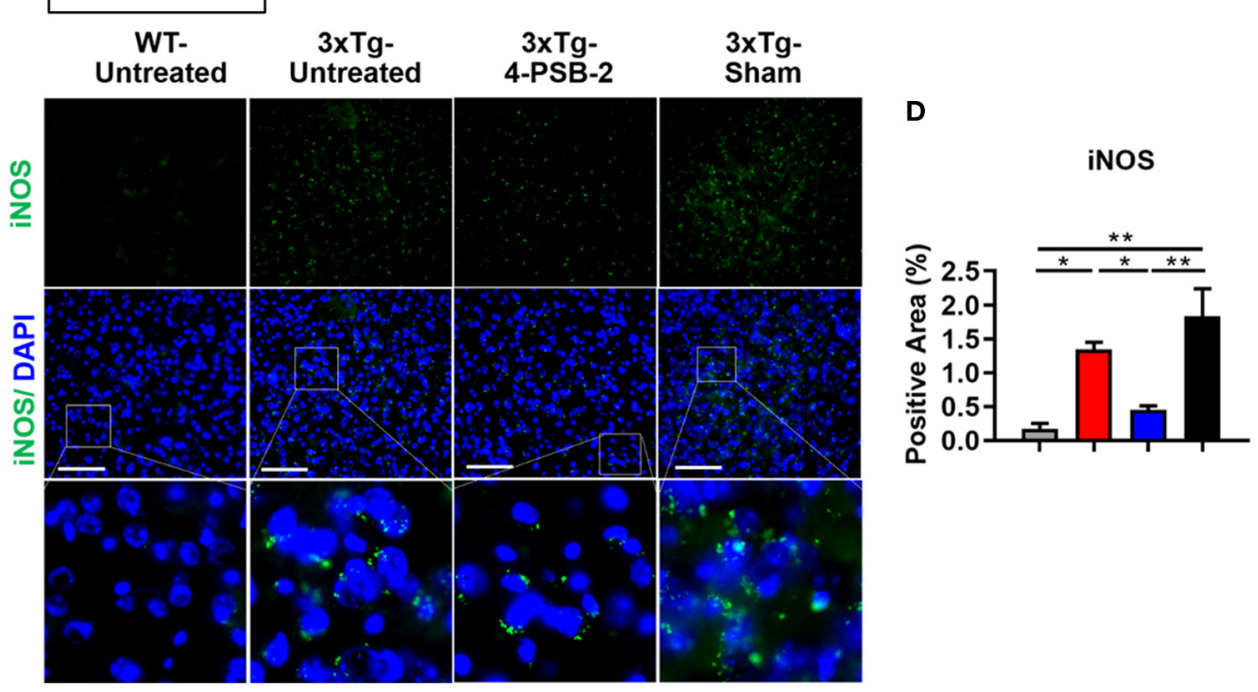

FIGURE 5 | 4-PSB-2 suppressed iNOS expression in the hippocampal CA3 region and BLA of 3xTg-AD mice after TFC. (A,B) The expression of iNOS in the hippocampal CA3 region was significantly increased in the untreated 3xTg-AD and sham groups and was significantly decreased after 4-PSB-2 administration. (C,D) The expression of iNOS in the BLA of the untreated 3xTg-AD and sham groups were upregulated after TFC. After 4-PSB-2 administration, iNOS expression was also suppressed (compared with that in the sham group). The results are plotted as the means \pm SEMs. * indicates $p \leq 0.05$, and ${ }^{* *} I$ ndicates $p \leq 0.001$ between the groups. iNOS (green) and DAPI (blue) (nuclei). Bar $=100 \mu \mathrm{m}$, and $n=3-5 /$ group.

CA1 region when compared with the untreated WT mice and were significantly decreased after 4 -PSB-2 treatment. In the dentate gyrus (DG), the expression levels of COX-2 and iNOS but not TNF- $\alpha$ in untreated and sham $3 x T g-A D$ mice were significantly increased, but were not decreased after 4-PSB-2 treatment (Supplementary Figures 2-4). We also detected the expression of $\mathrm{A} \beta$ oligomer (labeled with the A11 antibody) in the hippocampi and the BLA of 3xTg-AD mice. 3xTg-AD mice showed higher $A \beta$ expression than WT mice in the hippocampal CA1 $\left[F_{(3,87)}=20.968, p<0.001\right.$; Figures 6A,B $]$, CA3 $\left[F_{(3,71)}=\right.$ 14.669, $p<0.001$; Figures 6C,D $]$, dentate gyrus $\left[F_{(3,73)}=\right.$ 22.203, $p<0.001$; Figures 6E,F], and BLA $\left[F_{(3,62)}=7.479, p<\right.$ 0.001 ; Figures $6 \mathrm{G}, \mathrm{H}]$, but 4 -PSB- 2 treatment did not change $A \beta$ expression levels. 


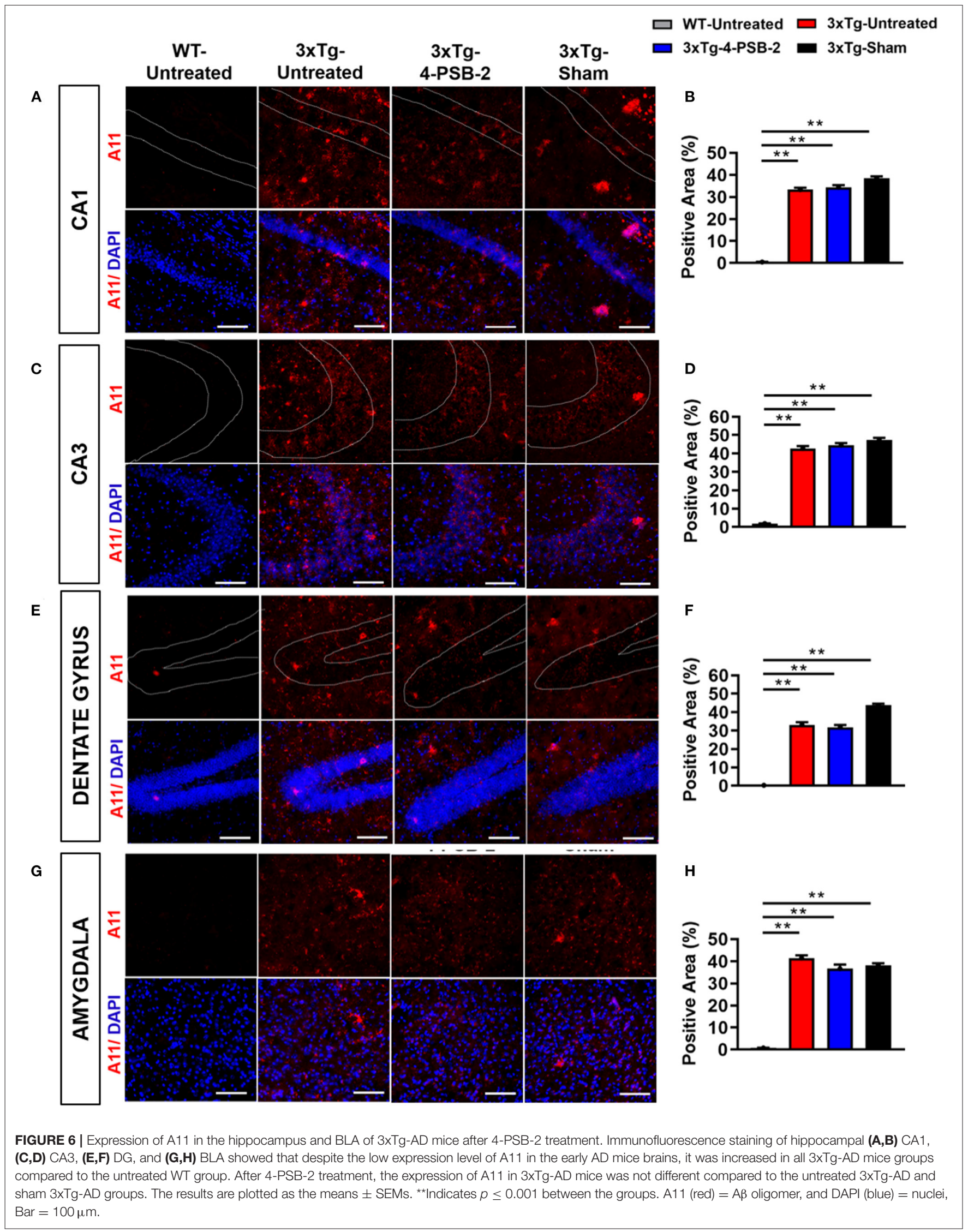



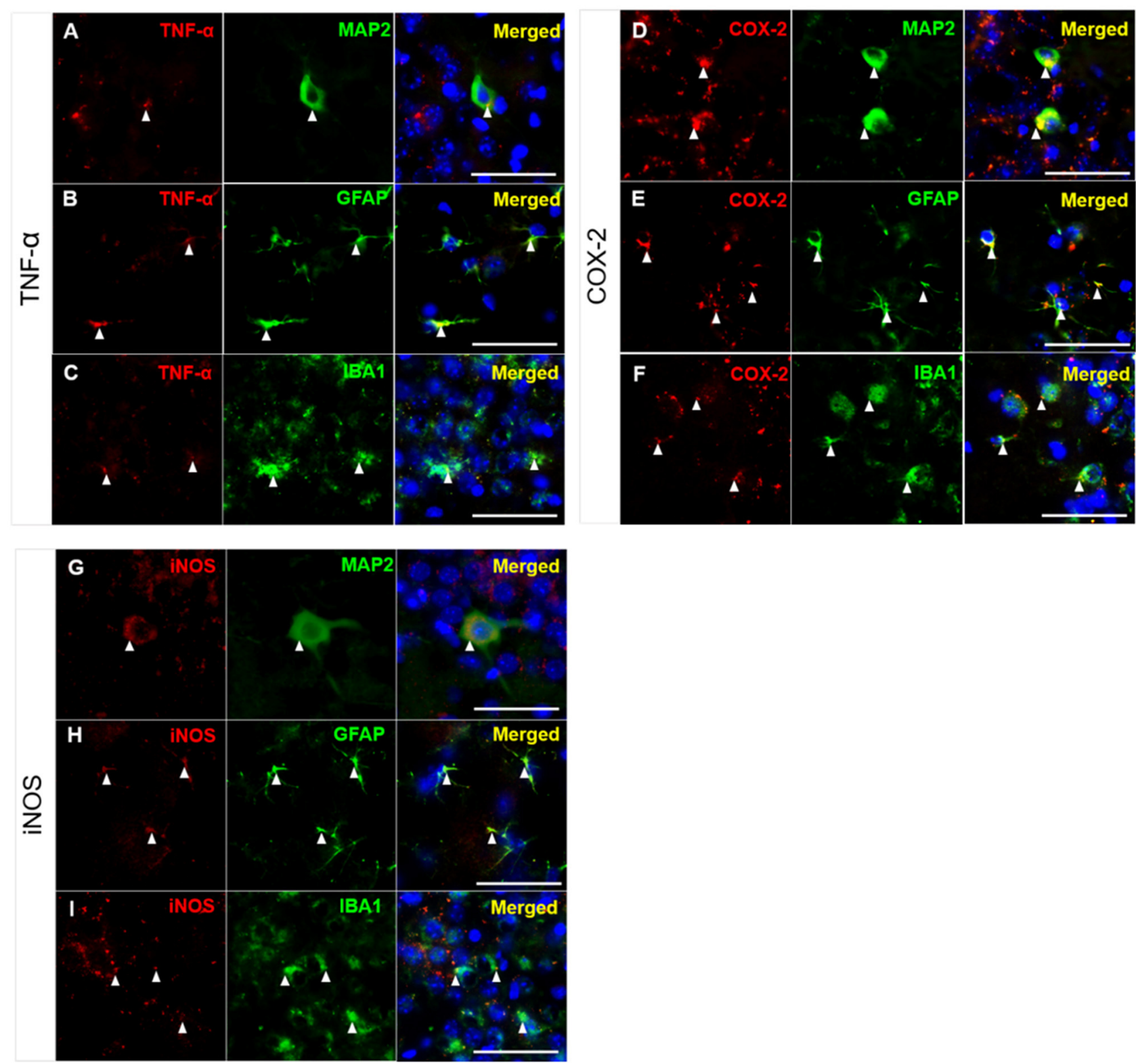

FIGURE 7 | Colocalization of inflammatory molecules with neuronal and glial markers in CA3 region of 3XTg-AD mice. Double immunofluorescence staining for (A-C) TNF, (D-F) COX-2, and (G-I) iNOS with MAP2, GFAP, and IBA1 in the hippocampal CA3 region in 3xTg-AD mice. The results demonstrated that TNF- $\alpha$, COX-2, and iNOS were detected in the cytoplasm of neurons (labeled with MAP2), astrocytes (labeled with GFAP), and microglial cells (labeled with IBA1), as indicated by the white arrowheads. TNF- $\alpha$, COX-2 and iNOS (red); MAP2, GFAP, and IBA1 (green); and DAPI (blue) (nuclei). Bar = $50 \mu \mathrm{m}$.

\section{Inflammatory Markers Were Expressed in the Cytoplasm of Neurons, Microglia, and Astrocytes in the Hippocampi of 3xTg-AD Mice After TFC}

As shown in Figures 4, 5, high levels of TNF- $\alpha$, COX-2, and iNOS were detected in the hippocampal CA3 region in the untreated $3 x$ Tg-AD group after TFC. We next aimed to identify the cell types in which these inflammatory markers were expressed. The brains of 3xTg-AD mice were collected after TFC for double staining with inflammatory markers (TNF- $\alpha$, COX-2, and iNOS), a neuronal marker (MAP2) or glial markers (GFAP for astrocytes and IBA1 for microglia). TNF- $\alpha$ was colocalized with MAP2 (Figure 7A), GFAP (Figure 7B), and IBA1 (Figure 7C) in the cytoplasm. TNF- $\alpha$ downstream targets, COX-2 and iNOS (Song et al., 2012), were also found to be colocalized with MAP2 (Figures 7D,G), GFAP (Figures 7E,H), and IBA1 (Figures 7F,I) in the cytoplasm. The results indicate that these inflammatory markers were expressed in all three cell types. 


\section{DISCUSSION}

In the present study, we report that 4-PSB-2 significantly rescues the impairment of fear memory retrieval in $3 \mathrm{xTg}-\mathrm{AD}$ mice and increases dendritic spine density and LTP through the suppression of several inflammation markers in the BLA and hippocampus (Graphical Abstract), particularly in the CA3region. Studies on $\mathrm{AD}$ patients have confirmed that atrophy (Basso et al., 2006) and functional disconnectivity (Ortner et al., 2016) of the hippocampus and BLA are associated with memory decline (Basso et al., 2006; Ortner et al., 2016). These two brain regions are known to be important for the retrieval and mediation of fear memory in nonAD mice (Anagnostaras et al., 2001; Gale et al., 2004; Lu et al., 2009). More internal synaptic connections existing in the hippocampal CA3-region than in other regions has been reported (Cherubini and Miles, 2015). Therefore, the loss of neurons and synaptic connectivity within the CA3-region may reduce the precision of memory retrieval (Chadwick et al., 2014) in $\mathrm{AD}$.

We further found that the inflammatory markers in the CA3region were expressed in neurons, microglia, and astrocytes of $3 x T g-A D$ mice. These inflammatory molecules seem to mediate cross-talk among these three types of cells. Microglia are glial cells that are responsible for homeostasis and immune defenses in the brain and can become polarized toward the proinflammatory M1 and immunosuppressive M2 phenotypes by $\mathrm{A} \beta$ deposition (Fakhoury, 2018). In $\mathrm{AD}$, an excess of $\mathrm{A} \beta$ deposition disrupts the balance between M1 and M2 microglia, resulting in the overexpression of proinflammatory molecules (IL- $1 \beta$, TNF- $\alpha$, iNOS, and IL-6), in turn causing neuronal damage (Tang and Le, 2016). The increase of proinflammatory molecules such as LPS, IL- $1 \beta$, TNF- $\alpha$, and IFN- $\gamma$ also interfered with the microglia's capacity to remove $A \beta$ by suppressing microglial endocytic (SoleDomenech et al., 2016) and phagocytic activities (KoenigsknechtTalboo and Landreth, 2005). The microglial endocytosis can be improved by applying $40 \mathrm{~Hz}$ gamma oscillations to the brains of AD mice (Iaccarino et al., 2016). The microglial phagocytic activity can be improved with anti-inflammatory treatment (Koenigsknecht-Talboo and Landreth, 2005). Astrocytes are also activated by $A \beta$ and then secrete excessive inflammatory cytokines leading to neuronal injury (Fakhoury, 2018). Several studies have revealed that inflammatory cytokines such as the TNF- $\alpha$ (Yu et al., 2017), COX-2 (Chen et al., 2013), and iNOS (Lisboa et al., 2015) played important roles in regulating contextual fear memory. It is possible that in $\mathrm{AD}$ or aging mice, the inflammatory response is enhanced and lasts for long, which leads to over-activation of microglia and astrocytes in the CA3-region, resulting in neuronal function deficit, synaptic loss, synaptic transmission inefficiency (Mariani et al., 2017), and learning and memory impairment (Lana et al., 2016). Moreover, the brain areas other than the CA3-region and BLA are also affected by an enhanced inflammatory response in this transgenic AD mouse strain upon aging (Backman et al., 1999; Kinney et al., 2018). Therefore, more age-dependent memory tests need to be performed in $\mathrm{AD}$ mice to elucidate the relationship between changes of the inflammatory response in different brain regions.
The present study shows that 4-PSB-2 acts as a memory enhancer to increase contextual fear memory, elevate dendritic spine density, PSD-95 expression, and LTP in the hippocampus. The PSD-95 is a key protein that increases synaptic strength and the efficiency of the formation and retrieval of fear memory (Hering and Sheng, 2001; Fitzgerald et al., 2015; Huang et al., 2018). It is also known to regulate glutamatergic plasticity at the postsynaptic site (El-Husseini et al., 2000) and stabilizes $\alpha$ amino-3-hydroxy-5-methyl-4-isoxazolepropionic acid receptors (AMPARs) to promote synaptic function and spine growth (Chen et al., 2011). The reduction of PSD-95 and synaptic spine density can interfere with hippocampal LTP in AD mouse models (Tu et al., 2014; Gu et al., 2016). LTP is a well-accepted cellular representation of the synaptic plasticity indicating the efficiency of learning and memory. In the present study, we recorded reduced LTP from the Schaffer-collateral pathway, which sends efferent fiber from the CA3 to the CA1 regions of the hippocampus (Kumar, 2011; Cherubini and Miles, 2015). This phenomenon is in line with previous findings from other AD mouse models such as Tg2576 mice (Comery et al., 2005), APP/PS1 mice (Gu et al., 2016), and 5XFAD mice (Kimura and Ohno, 2009). Interestingly, the impaired LTP was reversed by 4-PSB-2 administration that has anti-inflammatory effects, indicating a relationship between levels of inflammation response with synaptic transmission.

The 4-PSB-2 has a similar chemical structure as BAY 117082 reported in a previous study (Lee et al., 2012), which can also suppress the expression of inflammatory proteins, including I $\mathrm{B}, \mathrm{NF}-\kappa \mathrm{B}$, and Akt. The structure of BAY 117082 varies slightly from that of 4 -PSB-2, as it contains a reactive Michael acceptor and a cyanide group in place of a ketone group. The structural similarities of the compounds probably underlie their similar functions in suppressing the inflammatory response. The 4-PSB-2 is likely able to pass through the blood-brain barrier since it is lipophilic and small; its molecular weight (180) is $<400$ Daltons (Pardridge, 2012). Our results are consistent with previous studies (Moy et al., 2004; Nakatani et al., 2009; Pearson et al., 2010), in which the "social recognition" of C57BL/6 remained intact with alterations to the "social novelty" behavior. The C57BL/6 mice in our study showed an increasing trend in "social novelty" behavior though not significant. This behavior was improved after 4PSB-2 treatment. The 4-PSB-2 was administered immediately after TFC because it is important for memory consolidation and inflammatory response induction (Barrientos et al., 2002; Johansen et al., 2011; White et al., 2020). Efficient memory consolidation in the hippocampus is known to help better memory retrieval (Bosshardt et al., 2005). Post-injection behavioral evaluation did not indicate any effect that 4-PBS2 seems to cause on anxiety test and locomotor activity of WT and 3xTg-AD mice, which suggests that 4-PSB-2 may be a good drug lead. It is noted that a single dose of 4PSB-2 used in this study did not significantly reduce $A \beta$ oligomer expression in the hippocampus (Shin et al., 2014) and BLA of 3xTg-AD mice; therefore, further time course studies of pharmacokinetics, toxicity, metabolism, and the effects of multiple doses are necessary. 
In conclusion, the excessive inflammatory response may be associated with impairment of fear memory retrieval occurred in early-stage AD. Our results demonstrate that targeting and reducing the inflammatory response in the brain with the 4PSB-2 may be a promising approach to prevent and treat related memory symptoms of $\mathrm{AD}$.

\section{DATA AVAILABILITY STATEMENT}

The original contributions presented in the study are included in the article/Supplementary Material, further inquiries can be directed to the corresponding author/s.

\section{ETHICS STATEMENT}

The animal study was reviewed and approved by The Institutional Animal Care and Use Committee of Tzu Chi University.

\section{AUTHOR CONTRIBUTIONS}

IL and PV developed hypotheses, designed and performed experiments, analyzed data, prepared Figures 2-7, Graphical Abstract, and wrote manuscript. KG developed hypotheses, performed the experiment, analyzed data, and prepared Figure 1. S-PH and SC developed hypotheses, designed experiments, and helped technical support. CE performed

\section{REFERENCES}

Akiyama, H., Barger, S., Barnum, S., Bradt, B., Bauer, J., Cole, G. M., et al. (2000). Inflammation and Alzheimer's disease. Neurobiol. Aging 21, 383-421. doi: 10.1016/S0197-4580(00)00124-X

Anagnostaras, S. G., Gale, G. D., and Fanselow, M. S. (2001). Hippocampus and contextual fear conditioning: recent controversies and advances. Hippocampus 11, 8-17. doi: 10.1002/1098-1063(2001)11:1<8::AID-HIPO1015>3.0.CO;2-7

Backman, L., Andersson, J. L., Nyberg, L., Winblad, B., Nordberg, A., and Almkvist, O. (1999). Brain regions associated with episodic retrieval in normal aging and Alzheimer's disease. Neurology 52, 1861-1870. doi: 10.1212/WNL.52.9.1861

Barrientos, R. M., Higgins, E. A., Sprunger, D. B., Watkins, L. R., Rudy, J. W., and Maier, S. F. (2002). Memory for context is impaired by a post context exposure injection of interleukin-1 beta into dorsal hippocampus. Behav. Brain Res. 134, 291-298. doi: 10.1016/S0166-4328(02)00043-8

Basso, M., Yang, J., Warren, L., MacAvoy, M. G., Varma, P., Bronen, R. A., et al. (2006). Volumetry of amygdala and hippocampus and memory performance in Alzheimer's disease. Psychiatry Res. 146, 251-261. doi: 10.1016/j.pscychresns.2006.01.007

Billings, L. M., Oddo, S., Green, K. N., McGaugh, J. L., and LaFerla, F. M. (2005). Intraneuronal Abeta causes the onset of early Alzheimer's disease-related cognitive deficits in transgenic mice. Neuron 45, 675-688. doi: 10.1016/j.neuron.2005.01.040

Bosshardt, S., Degonda, N., Schmidt, C. F., Boesiger, P., Nitsch, R. M., Hock, C., et al. (2005). One month of human memory consolidation enhances retrieval-related hippocampal activity. Hippocampus 15, 1026-1040. doi: 10.1002/hipo.20105

Businaro, R., Corsi, M., Asprino, R., Di Lorenzo, C., Laskin, D., Corbo, R. M., et al. (2018). Modulation of inflammation as a way of delaying Alzheimer's disease progression: the diet's role. Curr. Alzheimer Res. 15, 363-380. doi: 10.2174/1567205014666170829100100 the experiment, analyzed data, and prepared Figure 1A and Table 1. PS helps with experimental designs, performed the experiment, and prepared the manuscript. Z-HW provided the compound and helped interpret results. All authors read and approved the final version of this manuscript.

\section{FUNDING}

This research was supported by Buddhist Tzu Chi Medical Foundation and Tzu Chi University (TCMMP 105-08-01, TCMFSP 108-04); and Ministry of Science and Technology (MOST), Taiwan (MOST-107-2410-H320-DOI-MY3).

\section{ACKNOWLEDGMENTS}

We sincerely thank Professor Hei-Jen Huang and Hsiu Mei Hsieh-Li for providing the 3xTg-AD mice. We also thank Tanita Parojana, Sarayut Phasuk, Shao-Fang Liang, Hsien-Ting Huang, and Kai-Chi Liang for helpful experimental assistance. We are grateful for the support from the Core Research Laboratory, Tzu Chi University.

\section{SUPPLEMENTARY MATERIAL}

The Supplementary Material for this article can be found online at: https://www.frontiersin.org/articles/10.3389/fnagi. 2021.615079/full\#supplementary-material

Chadwick, M. J., Bonnici, H. M., and Maguire, E. A. (2014). CA3 size predicts the precision of memory recall. Proc. Natl. Acad. Sci. U. S. A. 111, 10720-10725. doi: 10.1073/pnas.1319641111

Chen, R., Zhang, J., Fan, N., Teng, Z. Q., Wu, Y., Yang, H., et al. (2013). Delta9THC-caused synaptic and memory impairments are mediated through COX-2 signaling. Cell 155, 1154-1165. doi: 10.1016/j.cell.2013.10.042

Chen, X., Nelson, C. D., Li, X., Winters, C. A., Azzam, R., Sousa, A. A., et al. (2011). PSD-95 is required to sustain the molecular organization of the postsynaptic density. J. Neurosci. 31, 6329-6338. doi: 10.1523/JNEUROSCI.596810.2011

Cherubini, E., and Miles, R. (2015). The CA3 region of the hippocampus: how is it? What is it for? How does it do it? Front. Cell Neurosci. 9:19. doi: 10.3389/fncel.2015.00019

Chien, J. Y., Sheu, J. H., Wen, Z. H., Tsai, R. K., and Huang, S. P. (2016). Neuroprotective effect of 4-(Phenylsulfanyl)butan-2-one on optic nerve crush model in rats. Exp. Eye Res. 143, 148-157. doi: 10.1016/j.exer.2015.10.004

Comery, T. A., Martone, R. L., Aschmies, S., Atchison, K. P., Diamantidis, G., Gong, X., et al. (2005). Acute gamma-secretase inhibition improves contextual fear conditioning in the Tg2576 mouse model of Alzheimer's disease. J. Neurosci. 25, 8898-8902. doi: 10.1523/JNEUROSCI.2693-05.2005

El-Husseini, A. E., Schnell, E., Chetkovich, D. M., Nicoll, R. A., and Bredt, D. S. (2000). PSD-95 involvement in maturation of excitatory synapses. Science 290, 1364-1368. doi: 10.1126/science.290.5495.1364

Fakhoury, M. (2018). Microglia and astrocytes in Alzheimer's disease: implications for therapy. Curr. Neuropharmacol. 16, 508-518. doi: 10.2174/1570159X15666170720095240

Fitzgerald, P. J., Pinard, C. R., Camp, M. C., Feyder, M., Sah, A., Bergstrom, H. C., et al. (2015). Durable fear memories require PSD-95. Mol. Psychiatry 20, 901-912. doi: 10.1038/mp.2014.161

Gale, G. D., Anagnostaras, S. G., Godsil, B. P., Mitchell, S., Nozawa, T., Sage, J. R., et al. (2004). Role of the basolateral amygdala in the storage of 
fear memories across the adult lifetime of rats. J. Neurosci. 24, 3810-3815. doi: 10.1523/JNEUROSCI.4100-03.2004

Garwood, C. J., Pooler, A. M., Atherton, J., Hanger, D. P., and Noble, W. (2011). Astrocytes are important mediators of Abeta-induced neurotoxicity and tau phosphorylation in primary culture. Cell Death Dis. 2:e167. doi: 10.1038 /cddis.2011.50

Gibb, R., and Kolb, B. (1998). A method for vibratome sectioning of Golgi-Cox stained whole rat brain. J. Neurosci. Methods 79, 1-4. doi: 10.1016/S0165-0270(97)00163-5

Gu, X. H., Xu, L. J., Liu, Z. Q., Wei, B., Yang, Y. J., Xu, G. G., et al. (2016). The flavonoid baicalein rescues synaptic plasticity and memory deficits in a mouse model of Alzheimer's disease. Behav. Brain Res. 311, 309-321. doi: 10.1016/j.bbr.2016.05.052

Hamann, S., Monarch, E. S., and Goldstein, F. C. (2002). Impaired fear conditioning in Alzheimer's disease. Neuropsychologia 40, 1187-1195. doi: 10.1016/S0028-3932(01)00223-8

Hering, H., and Sheng, M. (2001). Dendritic spines: structure, dynamics and regulation. Nat. Rev. Neurosci. 2, 880-888. doi: 10.1038/35104061

Huang, I. Y., Hsu, Y. L., Chen, C. C., Chen, M. F., Wen, Z. H., Huang, H. T., et al. (2018). Excavatolide-B enhances contextual memory retrieval via repressing the delayed rectifier potassium current in the hippocampus. Mar. Drugs 16:405, doi: $10.3390 / \mathrm{md} 16110405$

Iaccarino, H. F., Singer, A. C., Martorell, A. J., Rudenko, A., Gao, F., Gillingham, T. Z., et al. (2016). Gamma frequency entrainment attenuates amyloid load and modifies microglia. Nature 540, 230-235. doi: 10.1038/nature20587

Johansen, J. P., Cain, C. K., Ostroff, L. E., and LeDoux, J. E. (2011). Molecular mechanisms of fear learning and memory. Cell 147, 509-524. doi: 10.1016/j.cell.2011.10.009

Kawczak, P., Bober, L., and Baczek, T. (2018). Activity evaluation of some psychoactive drugs with the application of QSAR/QSPR modeling methods. Med. Chem. Res. 27, 2279-2286. doi: 10.1007/s00044-018-2234-5

Kimura, R., and Ohno, M. (2009). Impairments in remote memory stabilization precede hippocampal synaptic and cognitive failures in 5XFAD Alzheimer mouse model. Neurobiol. Dis. 33, 229-235. doi: 10.1016/j.nbd.2008.10.006

Kinney, J. W., Bemiller, S. M., Murtishaw, A. S., Leisgang, A. M., Salazar, A. M., and Lamb, B. T. (2018). Inflammation as a central mechanism in Alzheimer's disease. Alzheimers Dement. 4, 575-590. doi: 10.1016/j.trci.2018.06.014

Kishimoto, Y., Fukumoto, K., Nagai, M., Mizuguchi, A., and Kobashi, Y. (2017). Early contextual fear memory deficits in a double-transgenic amyloid-beta precursor protein/presenilin 2 mouse model of Alzheimer's disease. Int. J. Alzheimers Dis. 2017:8584205. doi: 10.1155/2017/8584205

Klein-Koerkamp, Y., Baciu, M., and Hot, P. (2012). Preserved and impaired emotional memory in Alzheimer's disease. Front. Psychol. 3:331. doi: $10.3389 /$ fpsyg.2012.00331

Koenigsknecht-Talboo, J., and Landreth, G. E. (2005). Microglial phagocytosis induced by fibrillar beta-amyloid and IgGs are differentially regulated by proinflammatory cytokines. J. Neurosci. 25, 8240-8249. doi: 10.1523/JNEUROSCI.1808-05.2005

Kumar, A. (2011). Long-term potentiation at CA3-CA1 hippocampal synapses with special emphasis on aging, disease, and stress. Front. Aging Neurosci. 3:7. doi: 10.3389/fnagi.2011.00007

Lana, D., Iovino, L., Nosi, D., Wenk, G. L., and Giovannini, M. G. (2016). The neuron-astrocyte-microglia triad involvement in neuroinflammaging mechanisms in the CA3 hippocampus of memory-impaired aged rats. Exp. Gerontol. 83, 71-88. doi: 10.1016/j.exger.2016.07.011

Lee, J., Rhee, M. H., Kim, E., and Cho, J. Y. (2012). BAY 11-7082 is a broadspectrum inhibitor with anti-inflammatory activity against multiple targets. Mediators Inflamm. 2012:416036. doi: 10.1155/2012/416036

Lisboa, S. F., Gomes, F. V., Silva, A. L., Uliana, D. L., Camargo, L. H., Guimaraes, F. S., et al. (2015). Increased contextual fear conditioning in iNOS knockout mice: additional evidence for the involvement of nitric oxide in stressrelated disorders and contribution of the endocannabinoid system. Int. J. Neuropsychopharmacol. 18:pyv005. doi: 10.1093/ijnp/pyv005

Lu, P., Mamiya, T., Lu, L. L., Mouri, A., Niwa, M., Hiramatsu, M., et al. (2009). Silibinin attenuates amyloid beta(25-35) peptide-induced memory impairments: implication of inducible nitric-oxide synthase and tumor necrosis factor-alpha in mice. J. Pharmacol. Exp. Ther. 331, 319-326. doi: 10.1124/jpet.109.155069
Mariani, M. M., Malm, T., Lamb, R., Jay, T. R., Neilson, L., Casali, B., et al. (2017), Neuronally-directed effects of RXR activation in a mouse model of Alzheimer's disease. Sci. Rep. 7:42270. doi: 10.1038/srep42270

Morrison, C. (2016). Hope for anti-amyloid antibodies surges, yet again. Nat. Biotechnol. 34, 1082-1083. doi: 10.1038/nbt1116-1082b

Moy, S. S., Nadler, J. J., Perez, A., Barbaro, R. P., Johns, J. M., Magnuson, T. R., et al. (2004). Sociability and preference for social novelty in five inbred strains: an approach to assess autistic-like behavior in mice. Genes Brain Behav. 3, 287-302. doi: 10.1111/j.1601-1848.2004.00076.x

Murray, C., Sanderson, D. J., Barkus, C., Deacon, R. M., Rawlins, J. N., Bannerman, D. M., et al. (2012). Systemic inflammation induces acute working memory deficits in the primed brain: relevance for delirium. Neurobiol. Aging 33, 603-616.e603. doi: 10.1016/j.neurobiolaging.2010. 04.002

Nakatani, J., Tamada, K., Hatanaka, F., Ise, S., Ohta, H., Inoue, K., et al. (2009). Abnormal behavior in a chromosome-engineered mouse model for human 15q11-13 duplication seen in autism. Cell 137, 1235-1246. doi: 10.1016/j.cell.2009.04.024

Nasrouei, S., Rattel, J. A., Liedlgruber, M., Marksteiner, J., and Wilhelm, F. H. (2020). Fear acquisition and extinction deficits in amnestic mild cognitive impairment and early Alzheimer's disease. Neurobiol. Aging 87, 26-34. doi: 10.1016/j.neurobiolaging.2019.11.003

Newcombe, E. A., Camats-Perna, J., Silva, M. L., Valmas, N., Huat, T. J., and Medeiros, R. (2018). Inflammation: the link between comorbidities, genetics, and Alzheimer's disease. J. Neuroinflamm. 15:276. doi: 10.1186/s12974-018-1313-3

Oddo, S., Caccamo, A., Shepherd, J. D., Murphy, M. P., Golde, T. E., Kayed, R., et al. (2003). Triple-transgenic model of Alzheimer's disease with plaques and tangles. Neuron 39, 409-421. doi: 10.1016/S0896-6273(03)00434-3

Ortner, M., Pasquini, L., Barat, M., Alexopoulos, P., Grimmer, T., Forster, S., et al. (2016). Progressively disrupted intrinsic functional connectivity of basolateral amygdala in very early Alzheimer's disease. Front. Neurol. 7:132. doi: 10.3389/fneur.2016.00132

Pai, C. S., Sharma, P. K., Huang, H. T., Loganathan, S., Lin, H., Hsu, Y. L., et al. (2018). The Activating transcription factor 3 (Atf3) homozygous knockout mice exhibit enhanced conditioned fear and down regulation of hippocampal GELSOLIN. Front. Mol. Neurosci. 11:37. doi: 10.3389/fnmol.2018.00037

Pardridge, W. M. (2012). Drug transport across the blood-brain barrier. J. Cereb. Blood Flow Metab. 32, 1959-1972. doi: 10.1038/jcbfm.2012.126

Pearson, B. L., Defensor, E. B., Blanchard, D. C., and Blanchard, R. J. (2010). C57BL/6J mice fail to exhibit preference for social novelty in the three-chamber apparatus. Behav. Brain Res. 213, 189-194. doi: 10.1016/j.bbr.2010.04.054

Rajendran, L., and Paolicelli, R. C. (2018). Microglia-mediated synapse loss in Alzheimer's disease. J. Neurosci. 38, 2911-2919. doi: 10.1523/JNEUROSCI.1136-17.2017

Scuderi, C., Bronzuoli, M. R., Facchinetti, R., Pace, L., Ferraro, L., Broad, K. D., et al. (2018). Ultramicronized palmitoylethanolamide rescues learning and memory impairments in a triple transgenic mouse model of Alzheimer's disease by exerting anti-inflammatory and neuroprotective effects. Transl. Psychiatry 8:32. doi: 10.1038/s41398-017-0076-4

Serrano-Pozo, A., Frosch, M. P., Masliah, E., and Hyman, B. T. (2011). Neuropathological alterations in Alzheimer disease. Cold Spring Harb. Perspect. Med. 1:a006189. doi: 10.1101/cshperspect.a006189

Shin, M. K., Kim, H. G., Baek, S. H., Jung, W. R., Park, D. I., Park, J. S., et al. (2014). Neuropep-1 ameliorates learning and memory deficits in an Alzheimer's disease mouse model, increases brain-derived neurotrophic factor expression in the brain, and causes reduction of amyloid beta plaques. Neurobiol. Aging 35, 990-1001. doi: 10.1016/j.neurobiolaging.2013.10.091

Sole-Domenech, S., Cruz, D. L., Capetillo-Zarate, E., and Maxfield, F. R. (2016). The endocytic pathway in microglia during health, aging and Alzheimer's disease. Ageing Res. Rev. 32, 89-103. doi: 10.1016/j.arr.2016.07.002

Song, S. B., Tung, N. H., Quang, T. H., Ngan, N. T., Kim, K. E., and Kim, Y. H. (2012). Inhibition of TNF-alpha-mediated NF-kappaB transcriptional activity in HepG2 cells by dammarane-type saponins from Panax ginseng leaves. J. Ginseng. Res. 36, 146-152. doi: 10.5142/jgr.2012.36.2.146

Tang, Y., and Le, W. (2016). Differential roles of M1 and M2 microglia in neurodegenerative diseases. Mol. Neurobiol. 53, 1181-1194. doi: $10.1007 /$ s12035-014-9070-5 
Tu, S., Okamoto, S., Lipton, S. A., and Xu, H. (2014). Oligomeric Abetainduced synaptic dysfunction in Alzheimer's disease. Mol. Neurodegener. 9:48. doi: 10.1186/1750-1326-9-48

Varinthra, P., Huang, S.-P., Chompoopong, S., Wen, Z.-H., and Liu, I. Y. (2020). 4-(phenylsulfanyl) butan-2-one attenuates the inflammatory response induced by amyloid- $\beta$ oligomers in retinal pigment epithelium cells. Mar. Drugs 19:1. doi: $10.3390 / \mathrm{md} 19010001$

Wahl, D., Coogan, S. C., Solon-Biet, S. M., de Cabo, R., Haran, J. B., Raubenheimer, D., et al. (2017). Cognitive and behavioral evaluation of nutritional interventions in rodent models of brain aging and dementia. Clin. Interv. Aging 12, 1419-1428. doi: 10.2147/CIA.S145247

Wang, Q., Xiao, B., Cui, S., Song, H., Qian, Y., Dong, L., et al. (2014). Triptolide treatment reduces Alzheimer's disease (AD)-like pathology through inhibition of BACE1 in a transgenic mouse model of AD. Dis. Model. Mech. 7, 1385-1395. doi: $10.1242 / \mathrm{dmm} .018218$

Wang, W. Y., Tan, M. S., Yu, J. T., and Tan, L. (2015). Role of pro-inflammatory cytokines released from microglia in Alzheimer's disease. Ann. Transl. Med. 3:136. doi: 10.3978/j.issn.2305-5839.2015.03.49

Wen, Z. H., Su, J. H., Huang, S. Y., Huang, C. Y., and Wen, Y.S. (2014). Pharmaceutical Composition for Whitening and/or Anti-inflammation. (R.O.C. patent No. TWI445553) Taiwan Intellectual Property Office. Available online at: https://twpat4.tipo.gov.tw/tipotwoc/tipotwkm?!!FR_I445553.

White, J. D., Urbano, C. M., Taylor, J. O., Peterman, J. L., Cooksey, M., Eimerbrink, M., et al. (2020). Intraventricular murine Abeta infusion elicits hippocampal inflammation and disrupts the consolidation, but not retrieval, of conditioned fear in C57BL6/J mice. Behav. Brain Res. 378:112303. doi: 10.1016/j.bbr.2019.112303
Wongrakpanich, S., Wongrakpanich, A., Melhado, K., and Rangaswami, J. (2018). A comprehensive review of non-steroidal anti-inflammatory drug use in the elderly. Aging Dis. 9, 143-150. doi: 10.14336/AD.2017.0306

Wotjak, C. T., and Pape, H. C. (2013). Neuronal circuits of fear memory and fear extinction. e-Neuroforum 4, 47-56. doi: 10.1007/s13295-013-0046-0

Wu, S. Y., Wang, H. M., Wen, Y. S., Liu, W., Li, P. H., Chiu, C. C., et al. (2015). 4-(Phenylsulfanyl)butan-2-one suppresses melanin synthesis and melanosome maturation in vitro and in vivo. Int. J. Mol. Sci. 16, 20240-20257. doi: 10.3390/ijms160920240

Yu, Z., Fukushima, H., Ono, C., Sakai, M., Kasahara, Y., Kikuchi, Y., et al. (2017). Microglial production of TNF-alpha is a key element of sustained fear memory. Brain Behav. Immun. 59, 313-321. doi: 10.1016/j.bbi.2016.08.011

Zhang, C., Wang, Y., Wang, D., Zhang, J., and Zhang, F. (2018). NSAID exposure and risk of Alzheimer's disease: an updated meta-analysis from cohort studies. Front. Aging Neurosci. 10:83. doi: 10.3389/fnagi.2018.00083

Conflict of Interest: The authors declare that the research was conducted in the absence of any commercial or financial relationships that could be construed as a potential conflict of interest.

Copyright (c) 2021 Varinthra, Ganesan, Huang, Chompoopong, Eurtivong, Suresh, Wen and Liu. This is an open-access article distributed under the terms of the Creative Commons Attribution License (CC BY). The use, distribution or reproduction in other forums is permitted, provided the original author(s) and the copyright owner(s) are credited and that the original publication in this journal is cited, in accordance with accepted academic practice. No use, distribution or reproduction is permitted which does not comply with these terms. 